\title{
A Model of Endogenous Nontradability and its Implications for the Current Account
}

\author{
Paul R. Bergin \\ Department of Economics, University of California at Davis \\ and NBER \\ Reuven Glick \\ Federal Reserve Bank of San Francisco
}

Prior draft: September 4, 2002

This draft: June 2, 2003

\begin{abstract}
:
This paper analyzes how a model where goods are endogenously nontraded can help explain the relationship between the current account and real exchange rate fluctuations. We formulate a small open economy two-period model in which goods switch endogenously between being traded or nontraded. The model demonstrates how movements in the real exchange rate and real interest rate can impose significant costs on intertemporal trade. The model also shows that a variety of nonlinear relationships is possible between the current account and real exchange rate, depending on the relative transport costs and substitutability in preferences between goods. In contrast to recent work, our analysis implies that such costs of intertemporal trade may be a concern for many countries, not just those with large current account imbalances.
\end{abstract}

Keywords: nontraded good, current account, exchange rate, transport cost JEL classification: F4

The views expressed below do not represent those of the Federal Reserve Bank of San Francisco or the Board of Governors of the Federal Reserve System. Research assistance by Marc Meredith is gratefully acknowledged.

P. Bergin / Department of Economics / University of California at Davis/ One Shields Ave. / Davis, CA 95616 USA prbergin@ucdavis.edu, ph (530) 752-8398, fax (530) 752-9382. 
R. Glick / Economic Research Department / Federal Reserve Bank of San Francisco / 101 Market Street, San Francisco, CA 96105 USA reuven.glick@sf.frb.org, ph (415) 974-3184, fax (415) 9742168. 


\section{Introduction}

Modern open-economy macroeconomics views the current account as a form of intertemporal trade, where countries borrow or lend to smooth their consumption levels across periods, while facing an intertemporal budget constraint and a real interest rate that reflects the price of borrowing. ${ }^{1}$ This intertemporal approach to the current account has long recognized that the existence of nontraded goods limits the ability of countries to engage in such intertemporal trade. In a classic contribution to this literature, Dornbusch (1983) showed that when some goods are nontradable, the interest rate faced by a country in making its intertemporal decisions can deviate greatly from the interest rate prevailing in the world capital market. For example, if a temporary rise in demand in a country generates a current account deficit, this rise in demand will tend to drive up the relative price of nontraded goods temporarily and hence the real exchange rate. The fluctuation in the real exchange rate effectively raises the real interest rate faced by this country, and dampens the optimal magnitude of the current account deficit. In this standard model, the cost of borrowing rises steadily and without bound as the country progressively tries to raise the level of current consumption by running ever larger current account deficits. ${ }^{2}$

This theory offers a useful explanation for some empirical regularities. As demonstrated in the classic puzzle of Feldstein and Horioka (1980), the current account imbalances observed in reality for developed countries tend to be smaller than simple theories suggest would be optimal. In contrast, real exchange rates generally are found to be excessively volatile. It long has been observed that international relative prices are many times more volatile than corresponding quantity variables, like the trade balance and current account (see Backus, et. al., 1992). The story above offers one simple way of understanding this relationship: a rise in demand in a country may lead endogenously to movements in the real exchange rate and real interest rate, and hence dampen current account imbalances. In this story, the larger is the fluctuation in the real exchange rate, the smaller is the movement in the current account.

Recent work in international macroeconomics has tried to deepen our understanding of nontraded goods by looking explicitly at the role of transportation costs, which the traditional literature

\footnotetext{
${ }^{1}$ See Obstfeld and Rogoff (1996) for a summary of this extensive literature.

${ }^{2}$ Dornbusch's model builds on the classic Salter-Swan one-period model of traded and nontraded goods.
} 
assumed lay implicitly behind the nontradability of some goods. ${ }^{3}$ Leading this effort, Obstfeld and Rogoff (2000) analyzed a two-period small open economy model with one home and one foreign good and trading frictions in the form of "iceberg" shipping costs. ${ }^{4}$ Their analysis agrees with the standard intertemporal literature's notion that a rise in borrowing raises the country's intertemporal price, as given by the real interest rate. But it departs from the standard literature in showing that the effect is highly nonlinear. In particular, the intertemporal price does not rise at all for small to medium-sized current account deficits, but it rises steeply when the imbalance becomes large. This implies that intertemporal trade costs are an issue only for countries in rather extreme circumstances with large current account deficits; countries that are starting off from levels near balance need not be concerned with rising intertemporal prices. It also has the odd implication that while the current account may fluctuate quite widely, there will be no movement in the real exchange rate. This stands in contrast to the empirical work demonstrating that the exchange rate in general is much more volatile than the current account.

This paper aims to deepen our understanding of the role of nontraded goods in intertemporal trade by formulating a more general model with multiple home goods. It shows that Obstfeld and Rogoff's result is by no means general; rather it shows that all countries, even those with modest current account imbalances, are likely to be subject to some degree of real exchange rate volatility and rising intertemporal costs. Generalizing the model from one to two home goods is sufficient to make this point. More broadly, we show how our more general two-good model is sufficiently rich to accommodate a range of nonlinear relationships between the current account and the intertemporal price. In fact, it is sufficient to nest the models of Obstfeld and Rogoff (2000) and Dornbusch (1983) together as special cases and make clear under which conditions each is relevant. These are found to depend jointly upon the relative transport costs and substitutability in preferences between the goods. Clearly, these are aspects of the problem that become apparent only when one extends the basic model of Obstfeld and Rogoff to include multiple home goods.

The central point of our analysis hinges on whether one thinks nontraded goods tend to exist

\footnotetext{
${ }^{3}$ See Dumas (1992) and Sercu, Uppal and Van Hulle (1995) for early papers incorporating explicit transportation costs of the type considered here. See Obstfeld and Rogoff (1996, Chapter 4), who embed transport costs in a dynamic Ricardian model of international trade. See also Betts and Kehoe (2001), who have explored the implications of transport costs for helping to explain real exchange rate behavior.
} 
during normal times when the current account is near balance. As long as nontraded goods exist, a rise in demand has the potential for raising their price and hence the overall price level in a small open economy. But when only one home good exists in the model, this good will tend to be exported to pay for imports of foreign goods in each period. This means that, except in extreme cases of current account imbalance occasioning the cessation of home good exports in that period, there are no nontraded goods. ${ }^{5}$

We would argue that this scenario surely must be unlikely, given that in reality, even in times of balanced trade, we observe that some goods are nontraded. A model with two home goods can allow for this important fact: one good with low transport costs is exported in general to pay for imported foreign goods, and the other good with high transport costs is not traded. The result is that even when one reformulates a theory of nontraded goods in terms of explicit trade costs that lie behind the nontradedness, one should expect the results in many ways to resemble those found in the standard literature that take nontradedness as exogenously given, at least in the neighborhood of balanced trade. We offer some simple empirical evidence to support this conclusion.

What then is the benefit of understanding nontradedness in terms of the trade costs that cause it? First, even if the standard analysis of Dornbusch holds for small current account imbalances, the model makes clear that because the tradability of goods is endogenous there are clear bounds on the range of imbalance over which this analysis holds. The price of nontraded goods can only rise so high before it becomes optimal to begin importing a good, and it ceases to be nontraded. In such a case, the traditional analysis breaks down and the intertemporal cost levels off. Our empirical work also offers support for this part of our conclusion.

A second reason for analyzing the issue in terms of explicit trade costs and endogenous nontradability is that there is substantial empirical work to support the importance of these elements. As Hummels $(1999,2001)$ has emphasized, trade costs -- including tariff and nontariff barriers, shipping costs, and other associated costs of marketing and distribution -- vary greatly across classes of goods and play an important role in trade decisions. Collecting detailed trade data for individual goods, he finds that freight costs alone can range from more than 30 percent of value for raw

\footnotetext{
${ }^{4}$ Obstfeld and Rogoff introduce a number of variant models to account for different "puzzles" in the open economy macro literature. The presence of trading costs for goods is the common feature of all.

${ }^{5}$ Even in this case the intertemporal budget constraint precludes the possibility of the home good being nontraded in all periods.
} 
materials and mineral fuels down to 4 percent for some manufactures. Empirical work has also found support for the idea that some goods do switch over time between status as traded and nontraded. Using a panel of U.S. manufacturing plants for 1987 to 1997, Bernard and Jensen (2001) find that year to year transition rates are significant: on average $13.9 \%$ of non-exporters begin to export in any given year during the sample, and $12.6 \%$ of exporters stop.

It would be natural to extend the analysis to a continuum of goods. But our analysis shows that it does not take a grand generalization of the model to an infinite number of goods to dissolve the particular nonlinearity found by Obstfeld and Rogoff; it only takes one extra good to have this effect. Further, it is easier to see precisely what causes this change when we keep the set of goods limited to this simple case. ${ }^{6}$

The next section of the paper will outline the theoretical model of trade costs and endogenous nontradedness. Section 3 will discuss the results more fully. Section 4 presents some suggestive empirical evidence in support of our main claims.

\section{The Model}

\section{1) Setup}

The model here will in many ways resemble that used in Obstfeld and Rogoff (2000). It is intentionally kept simple to enhance the intuition regarding trade costs, and extension of the model to a full general equilibrium setting with production is left to future work. As there, we analyze here a small open economy model with two periods. We differ primarily in considering the case of three goods (A, B, F), where the home country is endowed with two of them, rather than just one, as in Obstfeld-Rogoff. The home country's endowments of these two goods $\left(y_{A}, y_{B}\right)$ may be exported, imported, or nontraded. The third good is foreign, and can only be imported. The world has endowments of all three goods. The representative agent of the small country chooses consumption levels of the three goods $\left(c_{A}, c_{B}, c_{F}\right)$, which take on the domestic prices $\left(p_{A}, p_{B}, p_{F}\right)$. We

\footnotetext{
${ }^{6}$ Another benefit of assuming a finite number of goods is that our analysis below will be able to nest the model of Dornbusch (1983): for a particular range of current account balances, there will be one good that is consistently nontraded while the other good is consistently traded. This would no longer be possible under a continuum of goods, where at every point some good will be switching in and out of nontradedness, and hence the composition of the nontraded and traded goods sectors is continuously changing.
} 
consider an asset market where the representative agent of the country can trade a non-contingent bond $(B)$ with the rest of the world, which pays off at rate $i$, denominated in the units of the foreign good.

The prices of goods in the domestic market are affected by the presence of good-specific iceberg $\operatorname{costs}\left(\tau_{A}, \tau_{B}, \tau_{F}\right)$, where a certain fraction of each good disappears in transport. We assume that the home country pays for this cost, so that if the world price of good A is normalized to unity, the domestic price will be $p_{A}=\frac{1}{1+\tau_{A}}$ if the country exports good A, but $p_{A}=1+\tau_{A}$ if $\operatorname{good} \mathrm{A}$ is imported, and $\frac{1}{1+\tau_{A}}<p_{A}<1+\tau_{A}$ if good $\mathrm{A}$ is nontraded. The price of home good $\mathrm{B}$ is characterized by analogous price bounds. The price of the foreign good, which is always imported, is $p_{F}=1+\tau_{F}$. In proceeding, we will assume that the transportation cost for good A is at least as large as that for good B, i.e. $\tau_{A} \geq \tau_{B}$. As we shall see below, this implies A will be the "less tradable" good.

Home country consumption of the three goods is summarized by

$$
c_{t}=\left(c_{H t}^{(\theta-1) / \theta}+c_{F t}^{(\theta-1) / \theta}\right)^{\theta /(\theta-1)}
$$

where

$$
c_{H t}=\frac{c_{A t}^{\alpha} c_{B t}^{1-\alpha}}{\alpha^{\alpha}(1-\alpha)^{1-\alpha}} .
$$

Note that $\theta$ is the (constant) elasticity of substitution between the foreign good and the home good aggregate, while $\alpha$ denotes the expenditure shares for the two home goods in the home good aggregate. $^{7}$

The intratemporal optimization problem implies the following conditions for allocating consumption between the different goods for each period $t, t=1,2$ :

$$
\begin{aligned}
& c_{A t} / c_{H t}=\alpha\left(p_{A t} / p_{H t}\right)^{-1}, c_{B t} / c_{H t}=(1-\alpha)\left(p_{B t} / p_{H t}\right)^{-1} \\
& c_{H t} / c_{t}=\left(p_{H t} / p_{t}\right)^{-\theta}, c_{F t} / c_{t}=\left(p_{F t} / p_{t}\right)^{-\theta}
\end{aligned}
$$

\footnotetext{
${ }^{7}$ The Cobb-Douglas specification of the home good aggregate, of course, implies that the elasticity of substitution between the two home goods is unity.
} 
where the minimum-expenditure consumption-based price indices are defined as: ${ }^{8}$

$$
\begin{aligned}
& p_{H t} \equiv\left(p_{A t}\right)^{\alpha}\left(p_{B t}\right)^{1-\alpha} \\
& p_{t} \equiv\left(\left(\left(p_{A t}\right)^{\alpha}\left(p_{B t}\right)^{1-\alpha}\right)^{1-\theta}+\left(p_{F t}\right)^{1-\theta}\right)^{1 /(1-\theta)} .
\end{aligned}
$$

The intertemporal decision maximizes the two-period utility function

$$
\frac{1}{1-\eta}\left[\left(c_{1}\right)^{1-\eta}+\beta\left(c_{2}\right)^{1-\eta}\right]
$$

subject to the following intertemporal budget constraint:

$$
c_{1}=\left[\left(\frac{p_{A 1}}{p_{1}}\right) y_{A 1}+\left(\frac{p_{B 1}}{p_{1}}\right) y_{B 1}\right]+\left(\frac{p_{2}}{p_{1}(1+i)}\right)\left[\left(\frac{p_{A 2}}{p_{2}}\right) y_{A 2}+\left(\frac{p_{B 2}}{p_{2}}\right) y_{B 2}-c_{2}\right] .
$$

This implies the intertemporal Euler equation:

$$
\left(c_{2} / c_{1}\right)^{\eta}=\beta(1+i) \frac{p_{1}}{p_{2}}=\beta(1+r)
$$

where the real interest rate $1+r \equiv\left(p_{1} / p_{2}\right)(1+i)$. Note that the relevant interest rate for this intertemporal decision is the real interest rate $r$, which is expressed in units of the home consumption index, rather than simply the world interest rate, $i$, which is expressed in units of the foreign good. Given that the world price level is normalized to unity, the domestic real exchange rate is $(1 / p)$, and so $\left(p_{1} / p_{2}\right)$ represents the real exchange rate depreciation over time. The righthand side of condition (8) then simply represents the real interest rate parity condition. Movements in the real exchange rate then will influence the degree of borrowing or lending through their effect on the real interest rate. For simplicity, we normalize $i$ to zero in the analysis below.

\section{2) Solution}

Solving this system is a challenging task, given that there are "kinks" in the price schedules where the home goods A and B switch between being exported, nontraded, and imported. ${ }^{9}$ We follow

\footnotetext{
${ }^{8}$ Note that the price index expression for the home good does not contain a normalizing constant. For convenience, we chose to include the corresponding constant -- $1 /\left(\alpha^{\alpha}(1-\alpha)^{1-\alpha}\right)$-- in the specification for the home good consumption aggregate.

${ }^{9}$ Even though the "kinks" imply that the first derivatives of the price schedules for A and B are not defined at these points, we will show that prices still rise or fall monotonically.
} 
Obstfeld and Rogoff (2000) in conjecturing a sequence of trade adjustment according to which the home goods switch between being exported, nontraded, and imported in each period as aggregate consumption in period 1 increases. (The foreign good is always imported in both periods by assumption.) Corresponding to this sequence of trade adjustment is a sequence of price adjustment for each of the two home goods that satisfies the conditions for their intratemporal allocation.

Given this conjectured sequence of adjustment, we then solve analytically for the levels of period 1 aggregate consumption and the intertemporal aggregate price ratio in each of the regions that satisfy the intratemporal allocation conditions for the home and foreign goods as well as the intertemporal budget constraint. This permits us to determine the domestic consumption-based interest rate $r$, and, as in Obstfeld-Rogoff (2000), to trace out how this interest rate rises with current consumption (or current account deficits). This enables us to analyze how relative transport costs and the pattern of trade affect the level of intertemporal trade, which is our objective here. ${ }^{10}$ We verify the optimality of the conjectured sequence of adjustment by showing that it implies a monotonically increasing schedule for the real interest rate as first-period consumption rises.

Table 1 presents our conjectured adjustment of export and import behavior and the corresponding prices of goods A and B. (The price of the foreign good is constant at $1+\tau_{F}$ throughout since it is always imported.) Thus in region I both of the home goods A and B are exported in period 1, implying $p_{A 1}=\frac{1}{1+\tau_{A}}, p_{B 1}=\frac{1}{1+\tau_{B}}$ and both are imported in period 2, implying $p_{A 2}=1+\tau_{A}, p_{B 2}=1+\tau_{B}$. In region IIa, A and B continue to be both exported in period 1 , while in period 2, importing of A ceases and no trading occurs, but B is still imported. As a result of the switch from being imported to being nontraded in period $2, p_{A 2}$ is no longer pinned down by foreign prices and transportation costs, and consequently falls below $1+\tau_{A}$. At the transition to region IIb, B ceases being imported and becomes nontraded in period 2 as well, and $p_{B 2}$ falls below $1+\tau_{B}$. The price of A, still nontraded, continues to decline. At the transition to region IIc, when $p_{B 2}$ has

\footnotetext{
${ }^{10}$ The resulting locus of $r$ and $c_{1}$ can be interpreted as a (partial) equilibrium "supply" schedule of foreign borrowing/lending. The Euler condition implies a corresponding "demand" schedule that can be used to determine the general equilibrium solution. Our analysis would be useful to examine the case of taste shocks which shift this demand schedule along the supply schedule, but we follow Obstfeld and Rogoff (2000) here in focusing our attention on the shape of the supply schedule.
} 
fallen to $\frac{1}{1+\tau_{B}}$, B starts being exported, while the price of A falls further. When in region III, $p_{A 2}=\frac{1}{1+\tau_{A}}$, and A begins to be exported as well. The transitions between regions IVa, IVb, IVc, and $\mathrm{V}$ are analogous, as first $\mathrm{A}$ and then $\mathrm{B}$ stops being exported in period $1 .^{11}$

To better understand how the relative price of home goods varies within and across regions, it is useful to solve the home good allocation conditions (2) for the following expression: ${ }^{12}$

$$
\frac{p_{A t}}{p_{B t}}=\gamma_{t}\left(\frac{c_{B t} / y_{B t}}{c_{A t} / y_{A t}}\right)
$$

where $\gamma_{t} \equiv(\alpha /(1-\alpha))\left(y_{B t} / y_{A t}\right)$. (9) describes how the relative prices of $\mathrm{A}$ and $\mathrm{B}$ in period t depend inversely on the relative consumptions of the two goods (expressed as ratios to their endowments), as well as on the parameter $\gamma_{t}$. When both goods are traded, as in regions I, III, and V, the prices of A and B are pinned down exogenously, and (9) determines the relative consumptions of the two goods. When one or both goods are nontraded, i.e. $c_{A t} / y_{A t}=1$ and possibly $c_{B t} / y_{B t}=1$, then (9) determines the relative prices of the goods in that period. For example, when both goods are nontraded, as in regions IIb for period 2 and IVb for period 1, then (9) implies $p_{A t} / p_{B t}=\gamma_{t}$, i.e. the relative price is equal to the constant $\gamma_{t}$. The parameter $\gamma_{t}$ reflects the role of relative preferences and endowments on the relative price of the two home goods.

We next map the conjectured sequence of trade and price adjustment to the level of aggregate consumption by determining the lower and upper consumption bounds for which each of our regions applies. Denote the lower aggregate consumption bound in period 1 for regions IIa, IIb, ...V by $c_{1}^{\overline{I I a}}, c_{1}^{\overline{I l b}}, c_{1}^{\overline{I l c}} . c_{1}^{\overline{I I I}},{ }_{c_{1}}^{\overline{T V a}}, \overline{c_{1}^{\overline{V b}}}, c_{1}^{\overline{T V c}}, c_{1}^{\bar{V}}$, respectively. ${ }^{13}$ Hence $c_{1}^{I} \in\left\{0, c_{1}^{\overline{I I a}}\right\}, c_{1}^{I I a} \in\left\{c_{1}^{\overline{I l a}}, c_{1}^{\overline{I I b}}\right\}, \ldots$, $c_{1}^{V} \in\left\{c_{1}^{\bar{V}}, \infty\right\}$.

\footnotetext{
${ }^{11}$ The rationale for our numbering notation for regions will become apparent in Section III where we show our framework collapses to that of Obstfeld-Rogoff when $\tau_{A}=\tau_{B}$ and essentially there is only a single home good.

${ }^{12}$ The home goods allocation conditions jointly imply $p_{A t} c_{A t}=(\alpha /(1-\alpha)) p_{B t} c_{B t}$. Appropriate multiplying and dividing through by $y_{A t}$ and $y_{B t}$ gives (9).
} 
The consumption allocation conditions for good A and the home good composite expressions (2) and (3), respectively -- imply

$$
c_{t}=\left(p_{H t} / p_{t}\right)^{\theta} c_{H t}, c_{H t}=(1 / \alpha)\left(p_{A t} / p_{H t}\right) c_{A t} .
$$

Substituting the latter into the former and multiplying and dividing by $y_{A t}$ gives

$$
c_{t}=(1 / \alpha)\left(\frac{p_{A t}}{p_{H t}}\right)\left(\frac{p_{H t}}{p_{t}}\right)^{\theta}\left(\frac{c_{A t}}{y_{A t}}\right) y_{A t} .
$$

Note that this relationship holds for all regions as well as for each period $t, t=1,2$. We can derive analytic solutions for the consumption bounds of each region by substituting the corresponding prices of goods A and B at these bounds from Table 1 into expression (10).

Provided that the transportation cost on good A is at least as large as that on good B, i.e. $\tau_{A} \geq \tau_{B}$, we can show that the cutoffs between regions lie in the following order (see Appendix Table 1):

$$
c_{1}^{\overline{I I a}}<c_{1}^{\overline{I I b}}<c_{1}^{\overline{I I c}}<c_{1}^{\overline{I I I}} \text { and } c_{1}^{\overline{I V a}}<c_{1}^{\overline{I V b}}<c_{1}^{\overline{I V c}}<c_{1}^{\bar{V}} .
$$

For all transportation costs below a certain threshold, $\tau *$, we further can show that there exists a set of parameter values for which

$$
c_{1}^{\overline{I I I}}<c_{1}^{\overline{I V a}} .
$$

This means that first-period consumption rises as goods switch in and out of tradability in the conjectured order. ${ }^{14}$

We next determine the schedule of real domestic interest rate and consumption values that satisfy the intratemporal allocation conditions for home and foreign goods as well as the intertemporal budget constraint. That is, as we increase $c_{1}$, we determine the corresponding levels of $p_{1} / p_{2}(=r$, since $i$ is normalized to 0 ) that satisfy (2), (3), and (7). We do so by substituting the appropriate prices of goods A and B into the expression for the intertemporal price ratio

\footnotetext{
${ }^{13}$ For increasing levels of $c_{1}$, the upper consumption bound of each region is equivalent to the lower consumption bound of the next region in the sequence.

${ }^{14}$ As we shall show below, there also exist parameter sets for which $c_{1}^{\overline{I I}}>c_{1}^{\overline{V v a}}$ and the sequence of trade adjustment differs from the one conjectured here.
} 


$$
\frac{p_{1}}{p_{2}}=\frac{\left(\left(p_{A 1}{ }^{\alpha} p_{B 1}^{1-\alpha}\right)^{1-\theta}+\left(1+\tau_{F}\right)^{1-\theta}\right)^{1 /(1-\theta)}}{\left(\left(p_{A 2}{ }^{\alpha} p_{B 2}{ }^{1-\alpha}\right)^{1-\theta}+\left(1+\tau_{F}\right)^{1-\theta}\right)^{1 /(1-\theta)}},
$$

where we have utilized the definition of the aggregate price level (5). ${ }^{15}$ Note that $p_{F t}=1+\tau_{F}$ since the foreign good is always imported in both periods. Appendix Table 2 gives expressions for the range of the intertemporal aggregate ratio in each region.

It is readily apparent that the real interest rate is constant for regions I, III, and V since all goods are traded in both periods and their prices then are determined exogenously. Moreover, in the case of region III, where both home goods are exported in both periods, the composite home goods price and hence the aggregate price are constant across time as well, implying $p_{1}=p_{2}$ and $r=1$.

When A and possibly B are nontraded, however, their prices vary with consumption, and the real interest rate is no longer constant. To determine how $p_{A t}$ and $p_{B t}$ change with $c_{t}$, we make use of the following equation (derived in Appendix B):

$$
p_{A t}^{\alpha} p_{B t}^{1-\alpha}=p_{F t}\left[\frac{1}{\left(c_{t} /\left[\left(c_{A t} / y_{A t}\right)^{\alpha}\left(p_{A t} / p_{B t}\right)^{1-\alpha}\left(y_{A t} / \alpha\right)\right]\right)^{(\theta-1) / \theta}-1}\right]^{1 /(1-\theta)} .
$$

Condition (12) gives us a general expression for $p_{A t}$ and $p_{B t}$ as a function of aggregate consumption, $c_{t}$, and good A consumption, $c_{A t}$, that holds for all regions and periods t. (Recall again that the price of the foreign good, $p_{F t}$, is always exogenously determined.) When $\mathrm{A}$ is nontraded $\left(c_{A t} / y_{A t}=1\right),(12)$ reduces to an expression for $p_{A t}$ as a function of $c_{t}$, conditional on $p_{B t}$. However, we know that when $B$ is traded its price is determined exogenously as either $1 /\left(1+\tau_{B}\right)$ when exported or $1+\tau_{B}$ when imported. When B as well as A are nontraded, expression (9) implies the price of B is proportional to that of A: $p_{A t}=p_{B t} \gamma_{t}$. Consequently, in both cases (12) enables the determination of $p_{A t}$ and $p_{B t}$ as we vary $c_{t}$. Plugging these home good prices into expression (12) for the intertemporal price ratio as we increase aggregate consumption gives us our desired $p_{1} / p_{2}-c_{1}$

\footnotetext{
${ }^{15}$ For example, for $c_{1}^{\overline{\Pi l}}, p_{A 1}=1+\tau_{A}, p_{B 1}=1+\tau_{B}$, implying $p_{H 1}=\left(1+\tau_{A}\right)^{\alpha}\left(1+\tau_{B}\right)^{1-\alpha}$, and hence $p_{1}=\left(\left(\left(1+\tau_{A}\right)^{\alpha}\left(1+\tau_{B}\right)^{1-\alpha}\right)^{1-\theta}+\left(1+\tau_{F}\right)^{1-\theta}\right)^{1 /(1-\theta)}$
} 
schedule.

Given the assumption that $\mathrm{A}$ is the less tradable good, we can order the intertemporal aggregate price ratios in the various regions as follows (see Appendix Table 2):

$$
\frac{p_{1}^{I I a}}{p_{2}^{I I a}}<\frac{p_{1}^{I I b}}{p_{2}^{I I b}}<\frac{p_{1}^{I I c}}{p_{2}^{I I c}}<\frac{p_{1}^{I I I}}{p_{2}^{I I I}}=1 \text { and } 1<\frac{p_{1}^{I V a}}{p_{2}^{I V a}}<\frac{p_{1}^{I V b}}{p_{2}^{I V b}}<\frac{p_{1}^{I V c}}{p_{2}^{I V c}}<\frac{p_{1}^{V}}{p_{2}^{V}}
$$

and when $c_{1}^{\overline{I I I}}<c_{1}^{\overline{I V a}}$ it will also be true that

$$
\frac{p_{1}^{I I I}}{p_{2}^{I I I}}<\frac{p_{1}^{I V a}}{p_{2}^{I V a}} .
$$

This steady rise in the price level of period 1 relative to that of period 2 indicates a rise in the consumption-based real interest rate. Accordingly, the regions defined above describe a steadily rising path for the consumption-based real interest rate as one begins with low levels of period-1

consumption and then lets consumption rise. In this sense our conjectured trade adjustment path is verified.

\section{Results}

\section{1) Benchmark case}

To develop intuition for the model above, consider a simple case where $10 \%$ of the foreign good disappears during international shipment. This is a modest and plausible value for many goods, and as this is the value assumed in Obstfeld and Rogoff (2000), it facilitates a comparison with their conclusions. Assume that the same iceberg cost applies to the home good B. But assume that the other class of home goods, A, is harder to transport, and a higher level of $25 \%$ disappears in shipment. ${ }^{16}$ These iceberg costs imply the following parameter values in our model: $\tau_{A}=1 / 3, \tau_{B}=\tau_{F}=1 / 9 .{ }^{17}$ For the elasticity of substitution between the foreign good and the home composite, a value of $\theta=6$ is a common choice in the literature, and is the value chosen by Obstfeld and Rogoff (2000) for their benchmark case. To focus the analysis on the role of transport costs and the elasticity of substitution, we assume a balanced preference and endowment path for

\footnotetext{
${ }^{16}$ Our assumed levels of trade costs are for illustrative purposes only. Of course, depending on tariff and nontariff barriers, shipping costs, and other associated costs of marketing and distribution, they can be much higher for some categories of goods. Hummels $(1999,2001)$ provides estimates of the possible range of trade costs across goods.
} 
home goods across time ( i.e. $\alpha=0.5, y_{A t}=y_{B t}=0.5$ ), implying that the relative price parameter $\gamma_{t} \equiv(\alpha /(1-\alpha))\left(y_{B t} / y_{A t}\right)=1$ for $t=1,2$

The implications of these transportation costs for the cost of intertemporal trade can be read easily by looking at figure 1 . This plots the ratio of the home price index in period 1 to that in period 2, which one may recall can be interpreted as the depreciation in the country's real exchange rate, given that the world price level is normalized to unity. Recall also that this ratio may be interpreted as the country's real interest rate, given that real interest rate parity holds and the world interest rate is normalized to unity. In the top panel this price ratio is plotted against the level of period-1 consumption for which it prevails. ${ }^{18}$ In the bottom panel, it is plotted against the period-1 current account as a share of total output, which is

$$
\frac{y_{H 1}-c_{1}}{y_{H 1}}
$$

where output is defined as

$$
y_{H 1} \equiv\left(\frac{p_{A 1}}{p_{1}}\right) y_{A 1}+\left(\frac{p_{B 1}}{p_{1}}\right) y_{B 1} .
$$

We list several observations below.

One observation from the graph is that as the level of consumption rises in period 1, the price index in period 1 rises steadily relative to that of period 2. This means that as the small open economy consumes progressively more and then begins to borrow in period 1 , the domestic real interest rate progressively rises, making borrowing more expensive. Unlike the analysis of Dornbusch (1983), however, the cost of borrowing does not rise forever as borrowing rises. Once period 1 consumption rises to the point that both home goods are imported in period 1 and exported in period 2 (in region $\mathrm{V}$ ), the domestic interest rate reaches its maximum deviation of 28 percent above the world interest rate level. ${ }^{19}$ Similarly, when consumption is very low (as in region I), the lower bound on the interest rate is

\footnotetext{
${ }^{17}$ The share lost in transport will equal $\tau /(1+\tau)$.

${ }^{18}$ Note that the figures suggest the possibility of negative consumption levels. Decreasing marginal utility or explicit nonnegative bounds when determining optimal consumption render these negative consumption levels as infeasible.

${ }^{19}$ Specifically, when both home goods are imported in period 1 and exported in period 2, the intertemporal price ratio is:
} 
22 percent below the world interest rate. While bounded, the range in the domestic interest rate induced by the endogenously nontraded goods is clearly very wide.

A second general observation is that goods with higher transportation costs tend to become nontraded first and to stop being nontraded last. In the figure, good A becomes nontraded before good B does. At a very low level of consumption in period 1 and hence a high level of consumption in period 2 (region I), both goods A and B are imported in period 2. Given that good A has a higher transport cost than B, its price must be higher when both goods are imported. As a result, the consumption of good B is higher than that of A, given the intratemporal optimization conditions. That is, since under the assumption $\gamma_{2}=1$ (9) implies

$$
\frac{c_{B 2} / y_{B 2}}{c_{A 2} / y_{A 2}}=\frac{p_{A 2}}{p_{B 2}}=\frac{1+\tau_{A}}{1+\tau_{B}}>1,
$$

it follows that $c_{A 2} / y_{A 2}<c_{B 2} / y_{B 2}$. Since the endowments of the two goods are assumed equal (i.e. $y_{A 2}=y_{B 2}$ ) it follows that $c_{A 2}-y_{A 2}<c_{B 2}-y_{B 2}$. Thus, as $c_{H 1}$ and $c_{1}$ rise and hence $c_{H 2}$ and $c_{2}$ fall, this will reduce consumption of both good A and B in the second period by the same proportionate amount. If output endowments are equal, the country will stop importing good A first in period 2, as characterized in the transition to IIa.

Further, in the figure good B stops being nontraded and becomes exported in period 2 before good A does. As period 1 consumption increases further in region IIa and the country continues to import B in period 2 at price $1+\tau_{B}$, the period 2 price of A falls from $1+\tau_{A}$ to $1+\tau_{B}$. Eventually, in region IIb the country ceases to import B in period 2 as well, consumption of both goods are equal to their common endowment levels, and hence both are nontraded $\left(c_{A 2} / y_{A 2}=c_{B 2} / y_{B 2}=1\right)$. In region $\mathrm{IIb}$, the prices of $\mathrm{A}$ and $\mathrm{B}$ are equalized in period 2 and with further increases in period 1 consumption and decreases in period 2 consumption fall together from $1+\tau_{B} \cdot{ }^{20}$ Eventually, in region

$$
\frac{p_{1}}{p_{2}}=\frac{\left(\left((1.2)^{0.5}(1.1)^{0.5}\right)^{1-6}+(1.1)^{1-6}\right)^{1 /(1-6)}}{\left(\left((1 /(1.2))^{0.5}(1 /(1.1))^{0.5}\right)^{1-6}+(1.1)^{1-6}\right)^{1 /(1-6)}}=1.1854
$$

\footnotetext{
${ }^{20}$ More precisely, when both goods are nontraded their prices are equalized when $\gamma_{2}=1$; otherwise they differ by $\gamma_{2}$, the constant scale factor that reflects the relative role of home good preferences and endowments on the relative price of $\mathrm{A}$ and $\mathrm{B}$.
} 
IIc, once the price of B and A falls to $1 /\left(1+\tau_{B}\right)$, B becomes exported, while A continues to be not traded, with its price falling further below $1 /\left(1+\tau_{B}\right)$. Only, in region III, when the price of A has fallen to $1 /\left(1+\tau_{A}\right)$, is $A$ as well as B exported in the second period. The transition between regions III through $\mathrm{V}$, as A and B switch from being exported to nontraded to imported in period 1 can be understood analogously.

A third general observation is that for small current account imbalances, there is no intertemporal price effect that dampens intertemporal trade. Note that in region III goods A and B are both exported in each period, and there is never any reversal in the pattern of trade of either good. In this region, the aggregate price index is constant over time and trade costs have no effects on the real interest rate. In this case the approximate balancing of exports with imports of the foreign good each period implies that the country is running a relatively small current account surplus or deficit. Thus for small variations of consumption and current account changes within this region, there will be no dampening effects of interest rate movements on international trade.

A final observation is that the cost of borrowing rises in a highly nonlinear way, rising most steeply as goods first become nontraded. Note that the curves in figure 1 become progressively steeper as they approach region III. Appendix C explains this behavior, which in large part results from the fact that the price index is concave in the price of home goods.

The main lessons here are that goods move through fairly complex phases of being traded or nontraded. This switching between categories means that the transport costs affect the goods prices in different ways at different times. But these effects of transport costs consistently work together to make the price index in a period rise when consumption in that period is high. This in turn translates into a high domestic real interest rate for the country, which makes high levels of consumption costly. This is how nontradedness discourages intertemporal trade.

\section{2) Nesting Obstfeld-Rogoff}

Our benchmark case differs from that of Obstfeld and Rogoff (2000) most importantly in that their case had only one home good with a single transport cost. We can exactly replicate this result for comparison with our benchmark, simply by assuming that there is a 10 percent loss from shipping for all goods $\left(\tau_{A}=\tau_{B}=\tau_{F}=1 / 9\right)$. Figure 2 depicts this case. 
A key observation is that the flat region III is much wider here. The current account must reach a level that is $35 \%$ of the country's output, either surplus or deficit, before the boundary of region III is reached. The reason is that with only one home good, for it to be nontraded requires that total gross exports be zero, that is, that the country exports nothing at all. The implication is that the nonlinear effects of nontraded goods highlighted by Obstfeld and Rogoff are likely never to be applicable for most countries, but only for those countries with extreme levels of current account imbalance. In addition, it also has the odd implication that while the current account may be fluctuating quite widely, there will be no movement in the real exchange rate. Yet existing empirical work suggests that the exchange rate is much more volatile than the current account.

However, the case of the model discussed in the preceding section demonstrates that by adding a second good with a larger transport cost, we can narrow this middle region, and bring the curved regions of the path closer together. As a result, goods become nontraded and have effects on the real interest rate at more modest levels of current account balance.

\section{3) Nesting Dornbusch}

For ever higher levels of transport cost, it is possible to bring the curved regions close enough together that the flat region III is eliminated altogether. Using our formulas (in Appendix Table 1) for the consumption bounds of region III -- $c_{1}^{\overline{I I I}}$ and $c_{1}^{\overline{I V a}}$-- we can compute the critical level of $\tau_{A}, \tau_{A}^{*}$, as that which satisfies the equation:

$$
\begin{aligned}
& c_{1}^{\overline{I I I}} \equiv\left(\frac{\left(1 /\left(1+\tau_{A}\right)\right) y_{A 1}+\left(1 /\left(1+\tau_{B}\right)\right) y_{B 1}}{\Omega^{1 /(1-\theta)}}\right)+\left(\frac{\left(1 /\left(1+\tau_{A}\right)\right) y_{A 2}+\left(1 /\left(1+\tau_{B}\right)\right) y_{B 2}}{\Omega^{1 /(1-\theta)}(1+i)}\right) \\
&-\left(\frac{(1 / \alpha)\left(1 /\left(1+\tau_{A}\right)\right)\left(1+\left(\frac{1+\tau_{F}}{1 /\left(1+\tau_{H}\right)}\right)^{1-\theta}\right) y_{A 2}}{\Omega^{1 /(1-\theta)}(1+i)}\right) \\
&=(1 / \alpha)\left(1 /\left(1+\tau_{A}\right)\right)\left(1+\left(\frac{1+\tau_{F}}{\left(\frac{1}{1+\tau_{H}}\right)}\right)^{1-\theta}\right)\left(\frac{1}{\Omega^{1 /(1-\theta)}}\right) y_{A 1} \equiv c_{1}^{\overline{I V b}}
\end{aligned}
$$


where

$$
\Omega \equiv\left(\frac{1}{1+\tau_{H}}\right)^{1-\theta}+\left(1+\tau_{F}\right)^{1-\theta} \quad \text { and } \quad 1+\tau_{H} \equiv\left(1+\tau_{A}\right)^{\alpha}\left(1+\tau_{B}\right)^{1-\alpha}
$$

For levels of transport cost that exceed this critical level $\tau_{A}^{*}$, the curved regions begin to overlap, i.e. $c_{1}^{\overline{I I I}}-c_{1}^{\overline{I V a}}<0$. See figure 3 for an example, where we assume that good A has an iceberg cost of 50\%: $\tau_{A}=1.0$ and $\tau_{B}=\tau_{F}=1 / 9$. In this case, the regions IIc and IVa overlap.

Given that region IIc implies that good A is nontraded in period 2, and region IVa implies that good A is nontraded in period 1, one might conjecture that good A would be nontraded in both periods here. This conjecture is indeed correct. In Table 2 we describe the sequence of adjustment of trade and prices when this new region is embedded in the benchmark case by "cutting into" regions IIc and IVa. We denote this case where A is nontraded while B is exported in both periods as region III' (since region III no longer exists). Determining the equilibrium consumption bounds and corresponding intertemporal price ratios for region III' requires the solution of nonlinear equations involving expression (12); see Appendix A for details.

In one sense, region III' is not really new. Recall that the analysis of Dornbusch (1983) focused on this very case, in which a good was nontraded in both periods. He found that, as consumption rises, the price of the nontraded good alters the price index over time and raises the real interest rate. He also found that the interest rate rises in percentage terms in a constant proportion to the rise in consumption in one period relative to the other. This property characterizes our region III' as well; we refer to this region as the "augmented Dornbusch case."

So what we have found is that, if the transportation cost of one of the goods rises sufficiently high, then we can create a case of our model which very neatly nests the analysis of Dornbusch within that of Obstfeld and Rogoff. This nesting of the traditional case within the cases suggested in recent theory, allows us to compare the two cases. This comparison leads to the conclusion that the slope of the line implied by the Dornbusch region in general will be steeper than the segments of the feasible Obstfeld-Rogoff regions. This is intuitively seen in figure 3, since a nearly straight line segment connecting two points must be steeper than the set of three zig-zagging line segments that it replaces, and these latter segments are in turn the steepest of the Obstfeld-Rogoff regions.

It is easy to understand why the Dornbusch case implies a larger effect of consumption 
changes on the real interest rate. Recall that it is the prices of nontraded goods that are able to rise or fall (within the bounds of their transportation costs) in response to consumption changes, and it is their effect on the overall price index that causes the real exchange rate and interest rate to move. This suggests that the impact on the real interest rate will be greatest in the case where the good with the highest transport costs is nontraded in both periods. ${ }^{21}$

Because in the Dornbusch region good A is nontraded in both periods, the price of good A may move in opposing directions between periods 1 and 2. Hence, because good A also has the highest transport costs and hence the widest bounds on its price each period, a simultaneous fall in the aggregate price one period and rise in the other allows large swings in the relative price between periods. In contrast, in the Obstfeld-Rogoff regions, either good A is nontraded in only one period, or goods A and B are both nontraded in only one period. Given that the transport cost on good B is smaller than that on good A, this implies smaller movements in aggregate prices between the two periods than in the Dornbusch region.

This suggests that the dampening effects of nontradability on intertemporal trade are greater in the Dornbusch case than are those that exist within the framework of Obstfeld and Rogoff. Further, these strong effects on the interest rate described by Dornbusch hit the country immediately as soon as it begins to move away from current account balance (since there is no flat region III). We would argue that the case supporting Dornbusch should be regarded as the more relevant, because it is consistent with the observation that the world appears to be characterized by the presence of many nontraded goods even in the presence of near current account balance.

Our model is also interesting because it suggests conditions under which Dornbusch's analysis may cease to apply. Because Dornbusch assumed that some goods were inherently nontradable, he could assume that his conclusions applied for any level of consumption, no matter how extreme. But if we acknowledge that goods are nontraded because of large but finite transportation costs, then there is a limit to where his analysis applies. In particular, we find here that if households wish to raise consumption enough, to the point that they begin to import the nontraded good, then Dornbusch's analysis no longer applies.

\footnotetext{
${ }^{21}$ It is possible to reverse this result if the good with the high transport cost is a sufficiently small share of the consumption bundle, and thereby has a small impact on the price index.
} 


\section{An Empirical Exploration}

Our model has several testable implications. First, it predicts a negative association of current balances and the real interest rate. Second, it implies a nonlinear relationship, such that changes in the real interest rate are largest for current account levels nearer to a zero balance. (We share the first implication with Obstfeld and Rogoff (2000), but the second implication stands in contrast to their model.) We test these hypotheses by extending the methodology in Obstfeld and Rogoff (2000) and Gordon and Bovenberg (1996), who conduct simple regressions of the real interest rate on the current account/GDP ratio.

The sample consists of annual data for 21 industrial countries (the 15 members of the European Union, except Luxembourg, plus Norway, Switzerland, Australia, Canada, Japan, New Zealand, and the United States) over the period 1975-1998. ${ }^{22}$ The real interest rate is constructed from a three-month nominal interest rate less the lagged annual inflation rate. All data are drawn from the IMF International Financial Statistics. For the nominal interest rate we use the short-term Treasury bill rate (line 60c) or a money market rate (line 60b) if the former is not available. The inflation rate is calculated from the CPI price index (line 64). The current account/GDP ratio was constructed by converting the current account balance in U.S. dollars (line 78ald) into local currency by the average \$- local currency exchange rate (line rf) and dividing by GDP (line 99b). We employ a fixed effect panel estimator adjusted for autoregressive errors ("xtregar" in Stata) with annual time dummies to capture common determinants of the real interest rate. Table 3 reports our results.

As with Obstfeld and Rogoff, we find a highly significant negative correlation between the current account and the real domestic interest rate: a one percent of GDP rise in the current account surplus is associated with a roughly 30 basis point decline in the real interest rate.

We test for the presence of nonlinearities in the sample in two ways. First, we introduce interaction terms to assess the extent to which the association varies with the magnitude of the current account imbalance. We consider dummy variables in turn for break points where the current account surplus or deficit is $0.5 \%, 1 \%, 5 \%$, and $10 \%$ of GDP. Obstfeld and Rogoff's analysis suggests that there should be no discernible relation between the interest rate and current account for small imbalances. In fact, we find that the sensitivity of the interest rate to current account imbalances is quite sensitive even for small deficits or surpluses. Moreover, we find that the sensitivity is highest for 
imbalances in the range of -0.5 to $0.5 \%$ of GDP.

The second way in which we investigate nonlinearity is by including quadratic terms for current account surpluses and deficits. The coefficients on both quadratic terms are each significant, and their signs support the conclusion in the test above: the sensitivity of the interest rate is greatest near current account balance, and this sensitivity levels out for larger current account imbalances. This conclusion is seen clearly in figure 4, which graphs the relationship estimated in the regression equation. Notably, this figure bears a resemblance to figure 3 , which was the theoretical relationship implied by the theoretical model for the augmented Dornbusch case. While the results of this brief empirical exploration are quite favorable to our theory, we caution that they are not a rigorous test, and should be interpreted merely as suggestive.

\section{Conclusions}

This paper has analyzed how trade costs and nontraded goods limit intertemporal trade. It showed how the effects found in past studies change if one does not assume a-priori that some goods are nontradable, but instead one allows nontradedness to arise endogenously because of large but finite transportation costs. In particular, a small open economy model with two home goods and one foreign good is used, where one of the two home goods is more costly to transport than the other.

The main implication is that even modest episodes of current account imbalance will induce movements in the real exchange rate and real interest rate, which will impose a cost on intertemporal trade. Such a finding may be helpful in explaining the observation that current account fluctuations tend to be small empirically relative to real exchange rate fluctuations. This stands in contrast to some recent research analyzing a special case where these costs take effect only for very large current account deficits. Our result implies that all countries, including those with small current account imbalances, may be affected by rising intertemporal prices.

Nevertheless, the model here indicates that the relationships between the current account and the real exchange rate and real interest rate may be nonlinear. The exact nature of this nonlinear relationship depends upon the relative trade costs between different goods and the degree of substitutability between these goods in preferences.

\footnotetext{
${ }^{22}$ We end the sample in 1998 just prior to formal adoption of the euro in 1999.
} 
There are some extensions of the model that would be natural to consider in future research. One such extension is a continuum of goods differentiated by trade costs. But our analysis shows that it does not take a grand generalization of the model to an infinite number of goods to demonstrate that the particular nonlinearity of Obstfeld and Rogoff is not a general result; it only required one additional home good to make the point that the nonlinearity can change qualitatively under multiple goods. In fact, it is easier to see precisely what causes this change when we keep the set of goods limited to this simple case. A further benefit of a finite number of goods is that it permitted us to identify a case where the model nests the conclusion of Dornbusch (1983), that is, where there was exactly one good that is consistently nontraded while the other good is consistently traded. This would no longer be possible under a continuum of goods, where at every point some good will be switching in and out of nontradedness, and hence the composition of the nontraded sector is continuously changing.

Another possible extension would be to generalize the endowment economy to consider endogenous production with heterogeneous productivities between goods. This raises the complex issue of how heterogeneity in terms of productivities would be correlated with heterogeneity in terms of trade costs, a modeling challenge left to future research. 


\section{References}

Backus, David K., Patrick J. Kehoe and Finn E. Kydland, 1992. "International Real Business Cycles, “ Journal of Political Economy, 100, 745-775.

Bernard, Andrew B. and J. Bradford Jensen, 2001. "Why Some Firms Export," NBER Working Paper 8394.

Betts, Caroline and Timothy Kehoe, 2001. "Tradability of Goods and Real Exchange Rate Fluctuations," Federal Reserve Bank of Minneapolis Research Department Staff Report.

Dornbusch, Rudiger, 1983. "Real Interest Rates, Home Goods and Optimal External Borrowing," Journal of Political Economy 91,141-53.

Dumas, Bernard, 1992. "Dynamic Equilibrium and the Real Exchange Rate in a Spatially Separated World," Review of Financial Studies 5, 153-180.

Feldstein, Martin, and Charles Horioka, 1980. "Domestic Savings and International Capital Flows," Economic Journal 90, 314-329.

Gordon, Roger H. and A. Lans Bovenberg, 1996. "Why Is Capital so Immobile Internationally? Possible Explanations and Implications for Capital Income Taxation," American Economic Review 86, 1057-1075.

Hummels, David, 1999. "Toward a Geography of Trade Costs," working paper, Purdue University. , 2001. "Time as a Trade Barrier," working paper, Purdue University.

Obstfeld, Maurice and Kenneth Rogoff, 1996. Foundations of International Macroeconomics. Cambridge, MA: the MIT Press. , 2000. "The Six Major Puzzles in International Macroeconomics: Is there a Common Cause," in Ben Bernanke and Kenneth Rogoff eds. NBER Macroeconomics Annual, Cambridge: MIT press, 339-390.

Sercu, Piet, Raman Uppal and Cynthia Van Hulle, 1995. "The Exchange Rate in the Presence of Transaction Costs: Implications for Tests of Purchasing Power Parity," Journal of Finance 50, 1309-1319. 
Table 1

Sequence of adjustment of home good trade and prices, benchmark case

\begin{tabular}{|c|c|c|c|c|c|c|c|c|}
\hline & Peri & od 1 & Peri & $\operatorname{lod} 2$ & Period & & Peri & \\
\hline Region & $\begin{array}{c}\text { Good } \\
\text { A }\end{array}$ & $\begin{array}{c}\text { Good } \\
\text { B }\end{array}$ & $\begin{array}{c}\text { Good } \\
\text { A }\end{array}$ & $\begin{array}{c}\text { Good } \\
\text { B }\end{array}$ & $p_{A 1} \uparrow$ & $p_{B 1} \uparrow$ & $p_{A 2} \downarrow$ & $p_{B 2} \downarrow$ \\
\hline I & $X$ & X & $\mathrm{M}$ & M & $\frac{1}{1+\tau_{A}}$ & $\frac{1}{1+\tau_{B}}$ & $1+\tau_{A}$ & $1+\tau_{B}$ \\
\hline IIa & $\mathrm{X}$ & X & NT & M & $\frac{1}{1+\tau_{A}}$ & $\frac{1}{1+\tau_{B}}$ & $\left\{1+\tau_{A}, \gamma_{2}\left(1+\tau_{B}\right)\right\}$ & $1+\tau_{B}$ \\
\hline IIb & $X$ & $X$ & NT & NT & $\frac{1}{1+\tau_{A}}$ & $\frac{1}{1+\tau_{B}}$ & $\left\{\gamma_{2}\left(1+\tau_{B}\right), \frac{\gamma_{2}}{1+\tau_{B}}\right\}$ & $\left\{1+\tau_{B}, \frac{1}{1+\tau_{B}}\right.$ \\
\hline IIc & X & $X$ & NT & $\mathrm{X}$ & $\frac{1}{1+\tau_{A}}$ & $\frac{1}{1+\tau_{B}}$ & $\left\{\frac{\gamma_{2}}{1+\tau_{B}}, \frac{1}{1+\tau_{A}}\right\}$ & $\frac{1}{1+\tau_{B}}$ \\
\hline III & $X$ & $X$ & $X$ & X & $\frac{1}{1+\tau_{A}}$ & $\frac{1}{1+\tau_{B}}$ & $\frac{1}{1+\tau_{A}}$ & $\frac{1}{1+\tau_{B}}$ \\
\hline IVa & NT & $X$ & $X$ & $X$ & $\left\{\frac{1}{1+\tau_{A}}, \frac{\gamma_{1}}{1+\tau_{B}}\right\}$ & $\frac{1}{1+\tau_{B}}$ & $\frac{1}{1+\tau_{A}}$ & $\frac{1}{1+\tau_{B}}$ \\
\hline $\mathrm{IVb}$ & NT & NT & $X$ & $X$ & $\left\{\frac{\gamma_{1}}{1+\tau_{B}}, \gamma_{1}\left(1+\tau_{B}\right)\right\}$ & $\left\{\frac{1}{1+\tau_{B}}, 1+\tau_{B}\right.$ & $\frac{1}{1+\tau_{A}}$ & $\frac{1}{1+\tau_{B}}$ \\
\hline IVc & NT & M & X & $X$ & $\left\{\gamma_{1}\left(1+\tau_{B}\right), 1+\tau_{A}\right\}$ & $1+\tau_{B}$ & $\frac{1}{1+\tau_{A}}$ & $\frac{1}{1+\tau_{B}}$ \\
\hline V & $\mathrm{M}$ & M & $X$ & $X$ & $1+\tau_{A}$ & $1+\tau_{B}$ & $\frac{1}{1+\tau_{A}}$ & $\frac{1}{1+\tau_{B}}$ \\
\hline
\end{tabular}

Note: $\mathrm{X}=$ export, $\mathrm{M}=$ import, $\mathrm{NT}=$ nontraded 
Table 2

Sequence of adjustment of home good trade and prices, Dornbusch case

\begin{tabular}{|c|c|c|c|c|c|c|c|c|}
\hline & Peric & od 1 & Peri & $\operatorname{lod} 2$ & Period & & Per & \\
\hline Region & $\begin{array}{c}\text { Good } \\
\text { A }\end{array}$ & $\begin{array}{c}\text { Good } \\
\text { B }\end{array}$ & $\begin{array}{c}\text { Good } \\
\text { A }\end{array}$ & $\begin{array}{c}\text { Good } \\
\text { B }\end{array}$ & $p_{A 1} \uparrow$ & $p_{B 1} \uparrow$ & $p_{A 2} \downarrow$ & $p_{B 2} \downarrow$ \\
\hline I & $X$ & $X$ & $\mathrm{M}$ & M & $\frac{1}{1+\tau_{A}}$ & $\frac{1}{1+\tau_{B}}$ & $1+\tau_{A}$ & $1+\tau_{B}$ \\
\hline IIa & $X$ & $X$ & NT & M & $\frac{1}{1+\tau_{A}}$ & $\frac{1}{1+\tau_{B}}$ & $\left\{1+\tau_{A}, \gamma_{2}\left(1+\tau_{B}\right)\right\}$ & $1+\tau_{B}$ \\
\hline $\mathrm{IIb}$ & $X$ & $X$ & NT & NT & $\frac{1}{1+\tau_{A}}$ & $\frac{1}{1+\tau_{B}}$ & $\left\{\gamma_{2}\left(1+\tau_{B}\right), \frac{\gamma_{2}}{1+\tau_{B}}\right\}$ & $\left\{1+\tau_{B}, \frac{1}{1+\tau_{B}}\right.$ \\
\hline IIc & $X$ & $X$ & NT & X & $\frac{1}{1+\tau_{A}}$ & $\frac{1}{1+\tau_{B}}$ & $\left\{\frac{\gamma_{2}}{1+\tau_{B}}, p_{A 2}^{\overline{I I I}}\right\}$ & $\frac{1}{1+\tau_{B}}$ \\
\hline III' & NT & $X$ & NT & $X$ & $\left\{\frac{1}{1+\tau_{A}}, p_{A 1}^{\overline{I V a}}\right\}$ & $\frac{1}{1+\tau_{B}}$ & $\left\{p_{A 2}^{\overline{I I I}}, \frac{1}{1+\tau_{A}}\right\}$ & $\frac{1}{1+\tau_{B}}$ \\
\hline IVa & NT & $X$ & $X$ & $X$ & $\left\{p_{A 1}^{\overline{I V a}}, \frac{\gamma_{1}}{1+\tau_{B}}\right\}$ & $\frac{1}{1+\tau_{B}}$ & $\frac{1}{1+\tau_{A}}$ & $\frac{1}{1+\tau_{B}}$ \\
\hline $\mathrm{IVb}$ & NT & NT & X & $X$ & $\left\{\frac{\gamma_{1}}{1+\tau_{B}}, \gamma_{1}\left(1+\tau_{B}\right)\right\}$ & $\left\{\frac{1}{1+\tau_{B}}, 1+\tau_{B}\right.$ & $\frac{1}{1+\tau_{A}}$ & $\frac{1}{1+\tau_{B}}$ \\
\hline IVc & NT & M & $X$ & X & $\left\{\gamma_{1}\left(1+\tau_{B}\right), 1+\tau_{A}\right\}$ & $1+\tau_{B}$ & $\frac{1}{1+\tau_{A}}$ & $\frac{1}{1+\tau_{B}}$ \\
\hline V & $\mathrm{M}$ & M & $X$ & $X$ & $1+\tau_{A}$ & $1+\tau_{B}$ & $\frac{1}{1+\tau_{A}}$ & $\frac{1}{1+\tau_{B}}$ \\
\hline
\end{tabular}

Note: $\mathrm{X}=$ export, $\mathrm{M}=$ import, $\mathrm{NT}=$ nontraded. See Appendix $\mathrm{A}$ for determination of $p_{A 1}^{\overline{V V a}}, p_{A 2}^{\overline{I I I a}}$. 
Table 3

Results from Empirical Estimations:

Real Interest Rates and the Current Account

Specification 1: dummies included at breakpoints for various $C A / G D P$ levels

\begin{tabular}{|c|c|c|c|c|c|}
\hline $\begin{array}{l}\text { threshold for } \\
\text { dummy (x) }\end{array}$ & $\frac{C A}{G D P}$ & $\begin{array}{l}\text { high surplus } \\
\text { dummy* }\end{array}$ & $\begin{array}{l}\text { high deficit } \\
\text { dummy** }\end{array}$ & $\rho$ & $R^{2}$ \\
\hline No dummy & $\begin{array}{c}-0.291 \\
(0.055)\end{array}$ & -- & -- & 0.579 & 0.357 \\
\hline$x=0.5 \%$ & $\begin{array}{l}-1.617 \\
(0.829)\end{array}$ & $\begin{array}{c}1.471 \\
(0.836)\end{array}$ & $\begin{array}{c}1.266 \\
(0.829)\end{array}$ & 0.598 & 0.342 \\
\hline$x=1 \%$ & $\begin{array}{c}-0.522 \\
(0.313)\end{array}$ & $\begin{array}{c}0.388 \\
(0.332)\end{array}$ & $\begin{array}{c}0.168 \\
(0.313)\end{array}$ & 0.599 & 0.344 \\
\hline$x=5 \%$ & $\begin{array}{c}-0.286 \\
(0.075)\end{array}$ & $\begin{array}{c}0.062 \\
(0.119)\end{array}$ & $\begin{array}{c}-0.022 \\
(0.072)\end{array}$ & 0.585 & 0.352 \\
\hline$x=10 \%$ & $\begin{array}{c}-0.342 \\
(0.065)\end{array}$ & $\begin{array}{c}0.190 \\
(0.193)\end{array}$ & $\begin{array}{c}0.120 \\
(0.082)\end{array}$ & 0.572 & 0.328 \\
\hline
\end{tabular}

Dummies enter regression as multiplying the $C A / G D P$ term.

*high surplus dummy indicates $C A / G D P>\mathrm{x}$, for the specified threshold $\mathrm{x}$.

**high deficit dummy indicates $C A / G D P<-\mathrm{x}$, for the specified threshold $\mathrm{x}$.

Specification 2: quadratic terms included

\begin{tabular}{ccccc}
\hline$\frac{C A}{G D P}$ & $\left(\frac{C A}{G D P}\right)^{2 *}$ & $-\left(\frac{C A}{G D P}\right)^{2 * *}$ & $\rho$ & $R^{2}$ \\
\hline $\begin{array}{l}-0.445 \\
(0.097)\end{array}$ & 0.043 & 0.053 & 0.589 & 0.325
\end{tabular}

*Applies for cases where $\mathrm{CA}>0$; value set to 0 otherwise.

**Applies for cases where $\mathrm{CA}<0$; value set to 0 otherwise.

Dependent variable is the real interest rate. Numbers in parentheses are standard errors. The sample consists of annual data for 21 industrial countries over the period 1975-1998, giving 471 observations. A fixed effect panel estimator with an autoregressive error correction $(\rho)$ is used ("xtregar" command in Stata); unreported constant term and annual time dummies are also included. 
Figure 1:

Two Good Benchmark Case

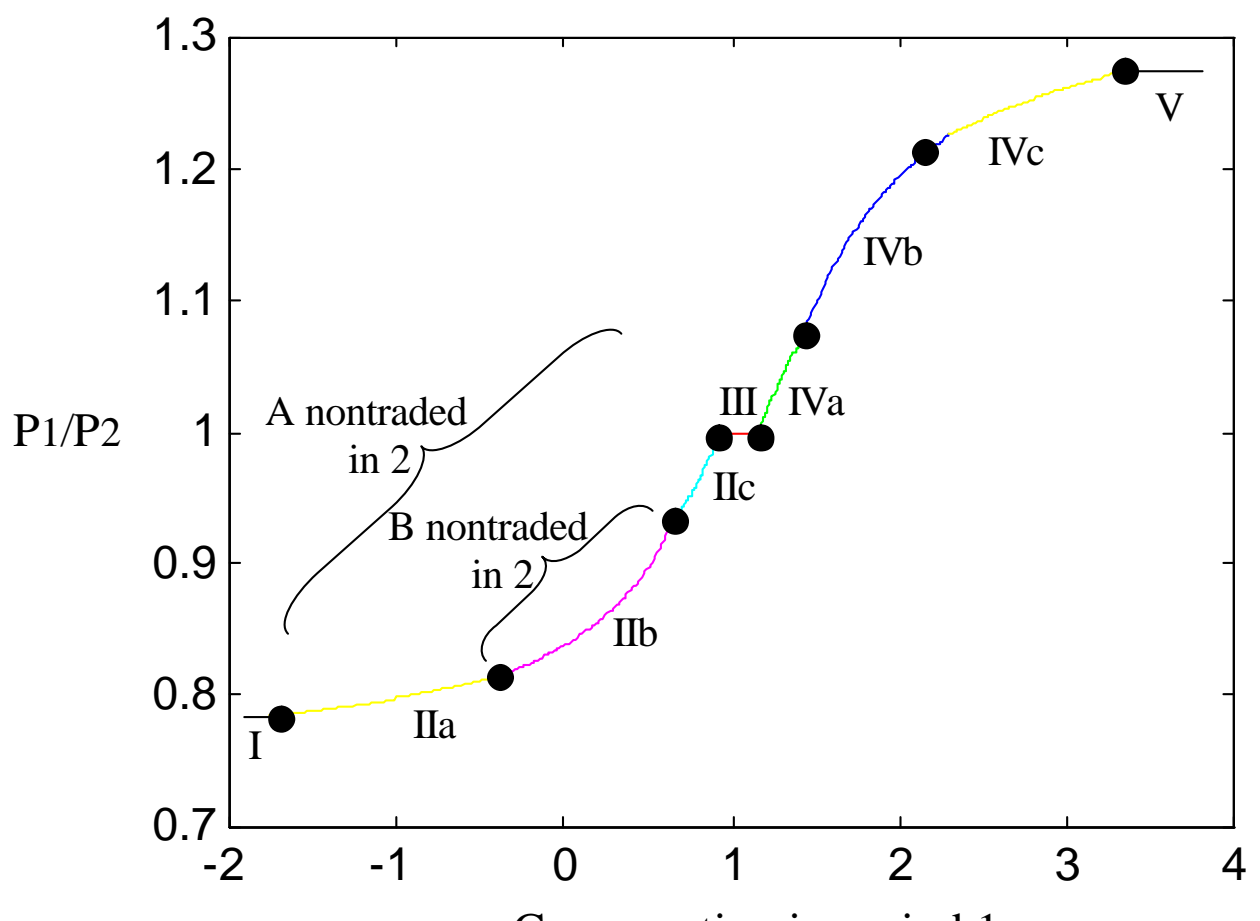

Consumption in period 1

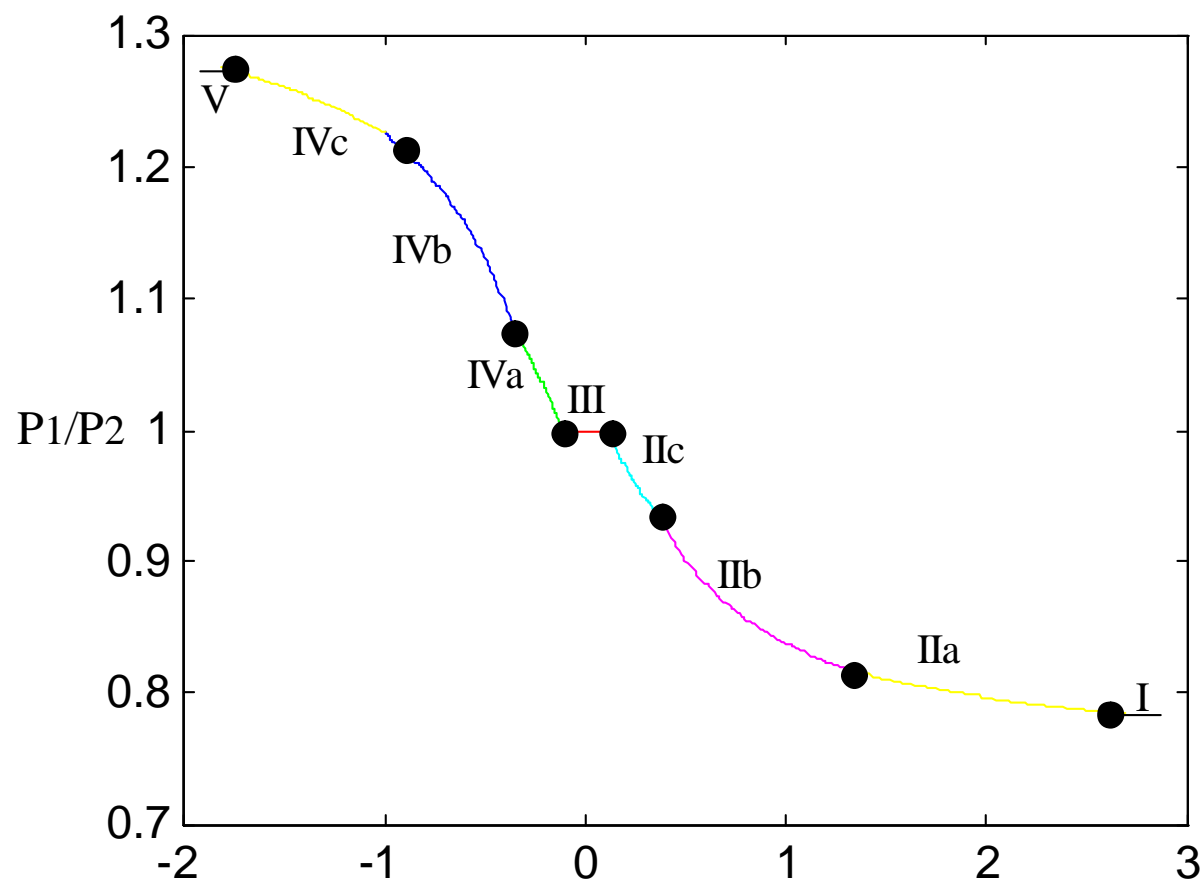

Current account in period 1 as a share of output

Parameter values: $\tau_{A}=1 / 3, \tau_{B}=\tau_{F}=1 / 9, \alpha=0.5, y_{A}=y_{B}=0.5, \theta=6$ 
Figure 2:

Simple One Good Case
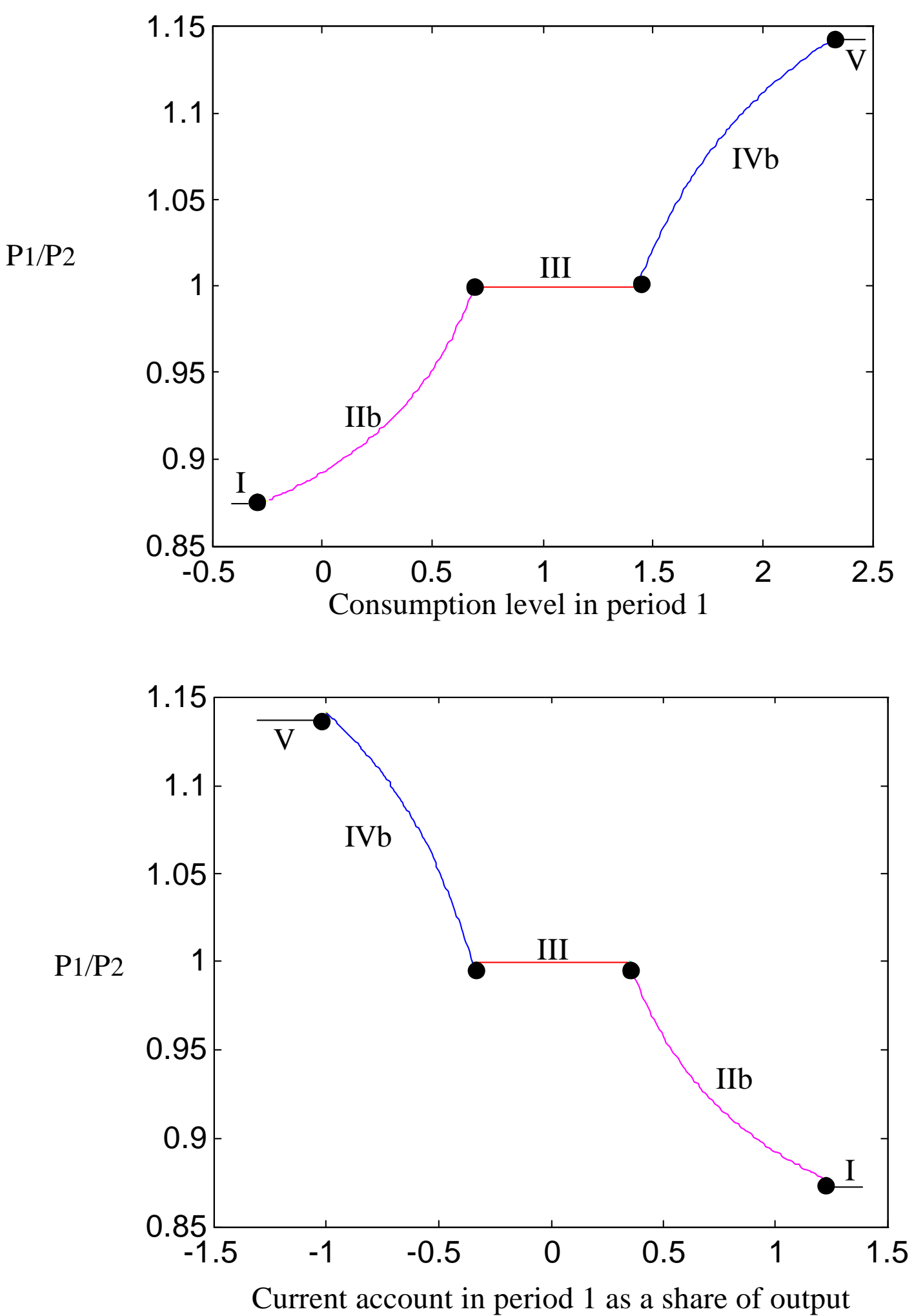

Parameter values: $\tau_{A}=\tau_{B}=\tau_{F}=1 / 9, \alpha=0.5, y_{A}=y_{B}=0.5, \theta=6$ 
Figure 3:

Nested Dornbusch Case
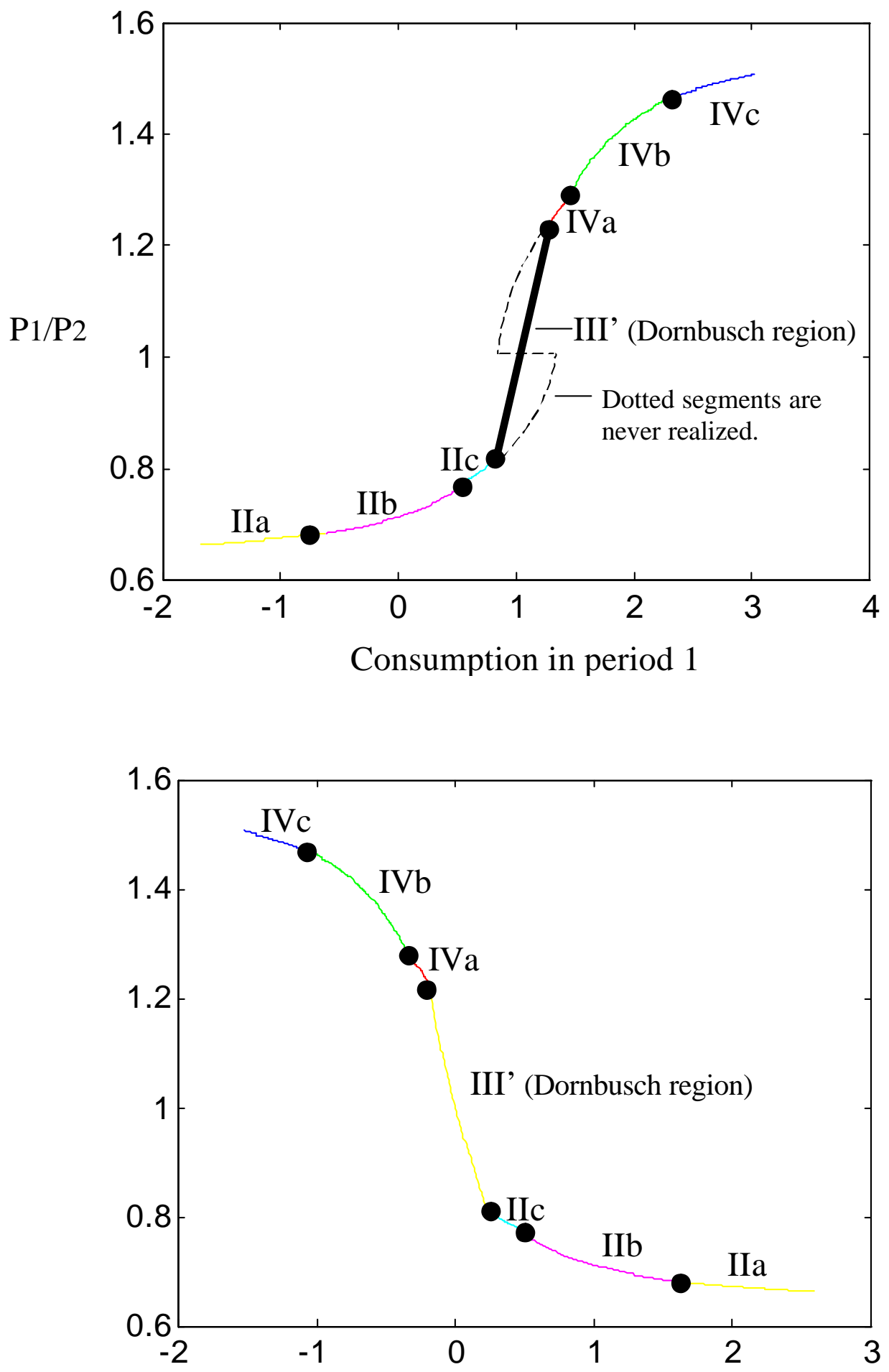

Current account in period 1 as a share of output

Parameter values: $\tau_{A}=1.0, \tau_{B}=\tau_{F}=1 / 9, \alpha=0.5, y_{A}=y_{B}=0.5, \theta=6$ 
Figure 4:

Empirical Relationship

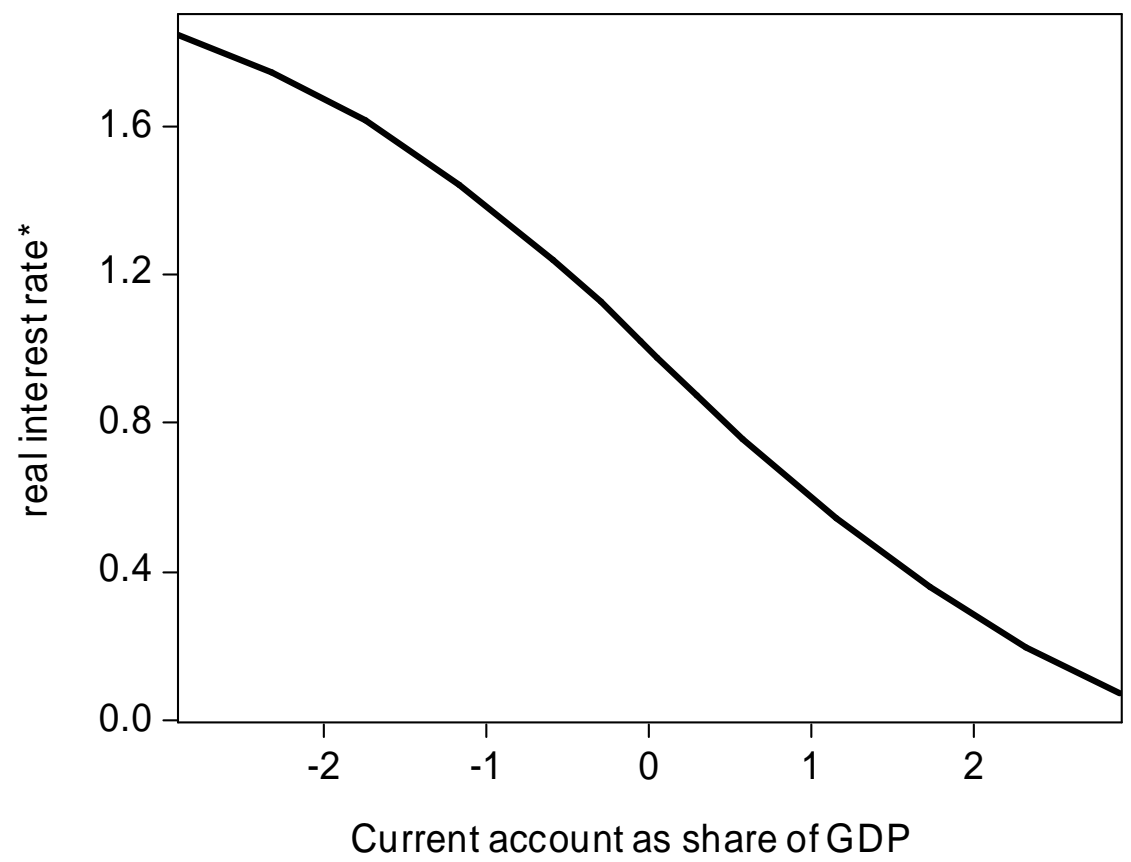

Assumes a quadratic relationship, with estimated coefficient values shown in table 3, specification 2.

* To facilitate comparison with previous graphs, the real interest rate shown is with a mean value renormalized to unity rather than zero. 


\section{Appendix}

\section{Appendix Part A. Derivation of boundary consumption levels}

Benchmark Case: Analytic solutions for the lower aggregate consumption bounds for the regions $\mathrm{IIa}, \mathrm{Ilb}, \ldots \mathrm{V}$ in Figure 1 may be derived by substituting the corresponding prices of goods $\mathrm{A}$ and $\mathrm{B}$ at these bounds from Table 1 into expression (10)

$$
c_{t}=(1 / \alpha)\left(\frac{p_{A t}}{p_{H t}}\right)\left(\frac{p_{H t}}{p_{t}}\right)^{\theta}\left(\frac{c_{A t}}{y_{A t}}\right) y_{A t},
$$

where the home and aggregate price levels are defined as

$$
\begin{aligned}
& p_{H t} \equiv\left(p_{A t}\right)^{\alpha}\left(p_{B t}\right)^{1-\alpha} \\
& p_{t} \equiv\left(\left(\left(p_{A t}\right)^{\alpha}\left(p_{B t}\right)^{1-\alpha}\right)^{1-\theta}+\left(p_{F t}\right)^{1-\theta}\right)^{1 /(1-\theta)} .
\end{aligned}
$$

More specifically, for regions IVa, IVb, and IVc where A is nontraded in period 1 (i.e. $c_{A 1} / y_{A 1}=1$ ), substitute the corresponding period 1 prices of goods A and B at these bounds into expression (10) for $t=1$ to determine $c_{1}^{\overline{I V a}}, c_{1}^{\overline{I V b}}, c_{1}^{\overline{I V c}}$, respectively. The corresponding consumption levels for period 2 then may be derived by substituting the period 1 consumption level and the relevant prices into the budget constraint (7).

For regions IIa, IIb, IIc, where A is nontraded in period 2 (i.e. $c_{A 2} / y_{A 2}=1$ ), the period 2 lower consumption bounds -- $c_{2}^{\overline{I I a}}, c_{2}^{\overline{I I b}}, c_{2}^{\overline{I c}}$, respectively -- are obtained by substituting the relevant period 2 prices into expression (10) for $t=2$. Substituting these period 2 consumption levels and the relevant prices into the budget constraint (7) then gives the corresponding consumption levels for period -- -- $c_{1}^{\overline{I I a}}, c_{1}^{\overline{I I b}}, c_{1}^{\overline{I l c}}$.

The analytic expressions for the period 1 consumption bounds are given in Appendix Table 1. It is straightforward to show that

$$
c_{1}^{\overline{I I a}}<c_{1}^{\overline{I I b}}<c_{1}^{\overline{I l c}}<c_{1}^{\overline{I I I}} \text { and } c_{1}^{\overline{I V a}}<c_{1}^{\overline{I V b}}<c_{1}^{\overline{I V c}}<c_{1}^{\bar{V}} .
$$

Dornbusch case: The consumption bounds for the Dornbusch case in which good A is nontraded in both periods, as in region III' of Figure 3, must be determined numerically. 
To determine the lower consumption bound for region III', first note that at the transition from region IIc to III' in period 1 good A just stops being exported and good B is still exported, implying the prices of both goods A and B are both pinned down in period 1:

$p_{A 1}^{\overline{I I I}}=1 /\left(1+\tau_{A}\right), p_{B 1}^{\overline{I I I}}=1 /\left(1+\tau_{B}\right)$. Since $\mathrm{A}$ is nontraded in period $1, c_{A 1} / y_{A 1}=1$ and we can determine $\quad c_{1}^{\overline{I I I}}\left(=c_{1}^{\overline{I V a}}\right)$ through (10) for $t=1$. Given $c_{1}^{\overline{I I T}}, p_{A 1}^{\overline{I I T}}$, and $p_{B 1}^{\overline{I I T}}$, the budget constraint (7)

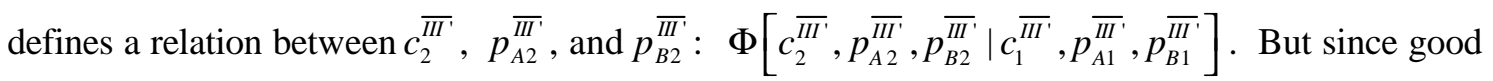
B is exported in period 2, its price is pinned down at $p_{B 2}^{\overline{I I T}}=1 /\left(1+\tau_{B}\right)$, and (10) reduces to a relation solely between $c_{2}^{\overline{I I I}}$ and $p_{A 2}^{\overline{I I \prime}}: \Phi\left[c_{2}^{\overline{I I I}}, p_{A 2}^{\overline{I I I}} \mid p_{B 2}^{\overline{I I I}}, c_{1}^{\overline{I I I}}, p_{A 1}^{\overline{I I I}}, p_{B 1}^{\overline{I I \prime}}\right]$

Note next that since A is nontraded in period $2, c_{A 2} / y_{A 2}=1$ and (9) and (12) for $t=2$ imply another relationship between $c_{2}^{\overline{I I I}}$ and $p_{A 2}^{\overline{I I '}}$, conditional on the exogenously given level of $p_{B 2}^{\overline{I I I}}$

$$
\left(p_{A 2}^{\overline{I I I}}\right)^{\alpha}\left(p_{B 2}^{\overline{I I I}}\right)^{1-\alpha}=p_{F 2}\left[\frac{1}{\left(c_{2}^{\overline{I I \prime}} /\left[\left(p_{A 2}^{\overline{I I I}} / p_{B 2}^{\overline{I I I}}\right)^{1-\alpha}\left(y_{A 2}, \alpha\right)\right]\right)^{(\theta-1) / \theta}-1}\right]^{1 /(1-\theta)} \equiv \Gamma\left[c_{2}^{\overline{I I \prime}}, p_{A 2}^{\overline{I I I}} \mid p_{B 2}^{\overline{I I I}}\right]
$$

Solving simultaneously the expressions $\Phi\left[c_{2}^{\overline{I I I}}, p_{A 2}^{\overline{I I I}} \mid p_{B 2}^{\overline{I I I}}, c^{\overline{I I I}}, p_{A 1}^{\overline{I I I}}, p_{B 1}^{\overline{I I I}}\right]$ and $\Gamma\left[c_{2}^{\overline{I I I}}, p_{A 2}^{\overline{I I I}} \mid p_{B 2}^{\overline{I I I}}\right]$ gives the equilibrium solutions for $p_{A 2}^{\overline{I I \prime}}$ and $c_{2}^{\overline{I I I}}$.

The lower bound value for region IVa, which is the same as the upper bound for region III', is determined analogously. In this case, A just starts being exported while B is still exported in period 2, pinning down their prices -- $\left.p_{A 2}^{\overline{V V a}}=1 /\left(1+\tau_{A}\right)\right)$ and $\quad p_{B 2}^{\overline{I V a}}=1 /\left(1+\tau_{B}\right)--$ and determining $c_{2}^{\overline{I V a}}\left(=c_{2}^{\overline{I I I}}\right)$ through (10) for $t=2$. Given $c_{2}^{\overline{I V a}}, p_{A 2}^{\overline{\text { TVa' }}}$, and $p_{B 2}^{\overline{\text { TVa'}}}$, the budget constraint (7) defines a relation between $c_{1}^{\overline{T V a}}, p_{A 1}^{\overline{T V^{\prime}}}$, and $p_{B 1}^{\overline{T V a}}$. But since good $\mathrm{B}$ is exported in period 1, its price is pinned down at $p_{B 1}^{\overline{V V a}}=1 /\left(1+\tau_{B}\right)$, and (10) reduces to a relation solely between $c_{1}^{\overline{V v a}}$ and $p_{A 1}^{\overline{V V a}}$. Expression (12) for $t=1$ gives a second equation involving $c_{1}^{\overline{V v a}}$ and $p_{A 1}^{\overline{T V a}}$, conditional on the exogenously given level of $p_{B 1}^{\overline{T V a}}$. Solving these two equations simultaneously gives the equilibrium solutions for $c_{1}^{\overline{I V a}}$ and $p_{A 1}^{\overline{V a}}$. 


\section{Appendix Part B. Derivation of expression (12)}

To derive (12), substitute the definition of the aggregate price (5),

$p_{t} \equiv\left(p_{H t}^{1-\theta}+p_{F t}^{1-\theta}\right)^{1 /(1-\theta)}$, into the allocation condition for the home good (3),

$c_{H t} / c_{t}=\left(p_{H t} / p_{t}\right)^{-\theta}$, and solve for $p_{H t}$ to get

$$
p_{H t}=p_{F t}\left[\frac{1}{\left(c_{t} / c_{H t}\right)^{(\theta-1) / \theta}-1}\right]^{1 /(1-\theta)} \text {. }
$$

To use this condition to express $c_{t}$ solely as a function of the prices and consumption of $\mathrm{A}$ and $\mathrm{B}$, we first substitute the definition of the composite home good price, $p_{H t}=p_{A t}{ }^{\alpha} p_{B t}{ }^{1-\alpha}$, on the lefthand side of (B.1).

$$
p_{A t}^{\alpha} p_{B t}^{1-\alpha}=p_{F t}\left[\frac{1}{\left(c_{t} / c_{H t}\right)^{(\theta-1) / \theta}-1}\right]^{1 /(1-\theta)} .
$$

Next, using the definition of the composite home goods consumption (1), $c_{H t} \equiv \frac{c_{A t}{ }^{\alpha} c_{B t}^{1-\alpha}}{\alpha^{\alpha}(1-\alpha)^{1-\alpha}}$, suitably multiplying and dividing through by $y_{A t}$ and $y_{B t}$, and recalling the notation $\gamma_{t} \equiv(\alpha /(1-\alpha))\left(y_{B t} / y_{A t}\right)$ gives $c_{H t}$ as a function of $c_{A t}$ and $c_{B t}$ :

$$
c_{H t}=\left(c_{A t} / y_{A t}\right)^{\alpha}\left(c_{B t} / y_{B t}\right)^{1-\alpha}\left(\gamma_{t}\right)^{1-\alpha}\left(y_{A t} / \alpha\right) .
$$

After using (9) to substitute for $c_{B t} / y_{B t}$, this reduces to

$$
c_{H t}=\left(c_{A t} / y_{A t}\right)^{\alpha}\left(p_{A t} / p_{B t}\right)^{1-\alpha}\left(y_{A t} / \alpha\right) \text {. }
$$

Substituting for $c_{H t}$ on the righthand side of (B.2) gives equation (12) in the text:

$$
p_{A t}^{\alpha} p_{B t}^{1-\alpha}=p_{F t}\left[\frac{1}{\left(c_{t} /\left[\left(c_{A t} / y_{A t}\right)^{\alpha}\left(p_{A t} / p_{B t}\right)^{1-\alpha}\left(y_{A t} / \alpha\right)\right]\right)^{(\theta-1) / \theta}-1}\right]^{1 /(1-\theta)} .
$$

\section{Appendix Part C. Explaining the curvature within region where goods are nontraded}

Rearrangement of the home goods allocation condition (3) implies

$$
p_{t}=p_{H t} /\left(c_{t} / c_{H t}\right)^{1 / \theta} \text {. }
$$


To make the analysis tractable, consider the case where there is only one home good (as in the model of Obstfeld and Rogoff (2000)) or where there are two home goods (as for our model in region $\mathrm{IVb}$ ) but both are nontraded, i.e. $c_{A t} / y_{A t}=c_{B t} / y_{B t}=c_{H t} / y_{H t}=1$. Then

$$
p_{t}=p_{H t} /\left(c_{t} / y_{H t}\right)^{1 / \theta} \text {. }
$$

Taking both sides to the power of $1-\theta$ and substituting in the definition of

$$
\begin{aligned}
p_{t} \equiv\left(p_{H t}{ }^{1-\theta}+p_{F t}{ }^{1-\theta}\right)^{1 /(1-\theta)} & \text { gives } \\
& p_{H t}^{1-\theta}+p_{F t}{ }^{1-\theta}=p_{H t}{ }^{1-\theta} /\left(c_{t} / y_{H t}\right)^{(1-\theta) / \theta} .
\end{aligned}
$$

Solving for $p_{H t}^{1-\theta}$

$$
p_{H t}^{1-\theta}=p_{F t}^{1-\theta}\left[\frac{\left(c_{t} / y_{H t}\right)^{(1-\theta) / \theta}}{1-\left(c_{t} / y_{H t}\right)^{(1-\theta) / \theta}}\right]
$$

Substituting for $p_{H t}^{1-\theta}$ back in the definition of $\mathrm{p}$ and solving for $\mathrm{p}$ :

$$
p_{t}=p_{F t}\left[\frac{1}{1-\left(c_{t} / y_{H t}\right)^{(1-\theta) / \theta}}\right]^{1 /(1-\theta)} .
$$

Consider how this formula applies to region IVb, where the composite home good is nontraded in period 1 and exported in period 2. In period $1, p_{H 1}$, and hence $p_{1}$, rise with $c_{1}$ in period 1 , according to the formula

$$
p_{1}=p_{F 1}\left[\frac{1}{1-\left(c_{1} / y_{H 1}\right)^{(1-\theta) / \theta}}\right]^{1 /(1-\theta)}
$$

while in period 2, the price of $\mathrm{H}$ is constant at $p_{H 2}=1 /(1+\tau)$; hence $p_{2}$ is constant as well. Thus, it is the rise in $p_{1}$ that generates the $p_{1} / p_{2}$ rises as $c_{1}$ increases in region IV.

The first derivative of the expression above is:

$$
\frac{\partial p_{1}}{\partial c_{1}}=\frac{p_{F 1}}{y_{H 1}} \frac{1}{\theta}\left[1-\left(\frac{c_{1}}{y_{H 1}}\right)^{\frac{1-\theta}{\theta}}\right]^{\frac{-2+\theta}{1-\theta}}\left(\frac{c_{1}}{y_{H 1}}\right)^{\frac{1-2 \theta}{\theta}}>0
$$

We know the derivative is positive, since we assume $\theta>1$ (demand is elastic), and we know that $c_{1} / y_{H 1}>1$ in region IV. This confirms the fact that $p_{1} / p_{2}$ rises as consumption rises.

To learn about the curvature, find the second derivative: 


$$
\begin{aligned}
& \frac{\partial^{2} p_{1}}{\partial c_{1}^{2}}= \frac{p_{F 1}}{y_{H 1}} \frac{1}{\theta}\left[1-\left(\frac{c_{1}}{y_{H 1}}\right)^{\frac{1-\theta}{\theta}}\right]^{\frac{-2+\theta}{1-\theta}}\left(\frac{1-2 \theta}{\theta}\right)\left(\frac{c_{1}}{y_{H 1}}\right)^{\frac{1-3 \theta}{\theta}}\left(\frac{1}{y_{H 1}}\right) \\
&-\frac{p_{F 1}}{y_{H 1}} \frac{1}{\theta}\left(\frac{c_{1}}{y_{H 1}}\right)^{\frac{1-2 \theta}{\theta}}\left(\frac{-2+\theta}{1-\theta}\right)\left[1-\left(\frac{c_{1}}{y_{H 1}}\right)^{\frac{1-\theta}{\theta}}\right]^{\frac{-3+2 \theta}{1-\theta}}\left(\frac{1-\theta}{\theta}\right)\left(\frac{c_{1}}{y_{H 1}}\right)^{\frac{1-2 \theta}{\theta}}\left(\frac{1}{y_{H 1}}\right) \\
&=\left\{\frac{p_{F 1}}{y_{H 1}{ }^{2}}\left(\frac{1-2 \theta}{\theta^{2}}\right)\left[1-\left(\frac{c_{1}}{y_{H 1}}\right)^{\frac{1-\theta}{\theta}}\right]^{\frac{-2+\theta}{1-\theta}}\left(\frac{c_{1}}{y_{H 1}}\right)^{\frac{1-3 \theta}{\theta}}\right\}\left\{1-\left(\frac{\theta-2}{1-2 \theta}\right)\left[\frac{\left(\frac{c_{1}}{y_{H 1}}\right)^{\frac{1-\theta}{\theta}}}{1-\left(\frac{c_{1}}{y_{H 1}}\right)^{\frac{1-\theta}{\theta}}}\right]\right\} .
\end{aligned}
$$

We consider in turn each of the two expressions in \{\} brackets.

1) We know that the left expression in \{\} is $<0$, since we assume $\theta>1$ (demand is elastic), and we know that $c_{1} / y_{H 1}>1$ in region IVb.

2) The sign of the right expression in \{\} depends on two parts:
a) $\left(\frac{\theta-2}{1-2 \theta}\right)$
$\in(0,1)$
for $1<\theta<2$
$<0$
for $\theta>2$
b) $\left[\frac{\left(\frac{c_{1}}{y_{H 1}}\right)^{\frac{1-\theta}{\theta}}}{1-\left(\frac{c_{1}}{y_{H 1}}\right)^{\frac{1-\theta}{\theta}}}\right]$

$$
\begin{array}{ll}
\in(0, \infty) & \text { for } 1<\theta<2 \\
\in(0, \infty) & \text { for } \theta>2
\end{array}
$$

We can conclude that the second derivative is negative for any value of $\theta>2$. For values of $\theta$ below this, the sign of the second derivative depends in a nontransparent way on the interaction between consumption levels, endowments, and the elasticity. This means that for the range of elasticities usually regarded as reasonable, the price level will indeed be concave in period-1 consumption in region IVb. 
Appendix Table 1. Boundary consumption levels: benchmark case

$$
\begin{aligned}
c_{1}^{\overline{I I a}}=\left[\frac{\left(1 /\left(1+\tau_{A}\right)\right) y_{A 1}+\left(1 /\left(1+\tau_{B}\right)\right) y_{B 1}}{\Omega^{1 /(1-\theta)}}\right]+\left[\frac{\left(1+\tau_{A}\right) y_{A 2}+\left(1+\tau_{B}\right) y_{B 2}}{\Omega^{1 /(1-\theta)}(1+i)}\right] \\
-\left[\frac{(1 / \alpha)\left(1+\left(\frac{1+\tau_{F}}{1+\tau_{H}}\right)^{1-\theta}\right)\left(1+\tau_{A}\right) y_{A 2}}{\Omega^{1 /(1-\theta)}(1+i)}\right]
\end{aligned}
$$$$
c_{1}^{\overline{I I b}}=\left[\frac{\left(1 /\left(1+\tau_{A}\right)\right) y_{A 1}+\left(1 /\left(1+\tau_{B}\right)\right) y_{B 1}}{\Omega^{1 /(1-\theta)}}\right]+\left[\frac{\gamma_{2}\left(1+\tau_{B}\right) y_{A 2}+\left(1+\tau_{B}\right) y_{B 2}}{\Omega^{1 /(1-\theta)}(1+i)}\right]
$$$$
-\left[\frac{\left(\gamma_{2} / \alpha\right)\left(1+\left(\frac{1+\tau_{F}}{\gamma_{2}^{\alpha}\left(1+\tau_{B}\right)}\right)^{1-\theta}\right)\left(1+\tau_{B}\right) y_{A 2}}{\Omega^{1 /(1-\theta)}(1+i)}\right]
$$$$
c_{1}^{\overline{I C c}}=\left[\frac{\left(1 /\left(1+\tau_{A}\right)\right) y_{A 1}+\left(1 /\left(1+\tau_{B}\right)\right) y_{B 1}}{\Omega^{1 /(1-\theta)}}\right]+\left(\frac{\left(\gamma_{2} /\left(1+\tau_{B}\right)\right) y_{A 2}+\left(1 /\left(1+\tau_{B}\right)\right) y_{B 2}}{\Omega^{1 /(1-\theta)}(1+i)}\right)
$$$$
-\left[\frac{\left(\gamma_{2} / \alpha\right)\left(1+\left(\frac{1+\tau_{F}}{\gamma_{2}^{\alpha} /\left(\left(1+\tau_{B}\right)\right)}\right)^{1-\theta}\right)\left(1 /\left(1+\tau_{B}\right)\right) y_{A 2}}{\Omega^{1 /(1-\theta)}(1+i)}\right]
$$

$$
\begin{aligned}
c_{1}^{\overline{I I I}}=\left(\frac{\left(1 /\left(1+\tau_{A}\right)\right) y_{A 1}+\left(1 /\left(1+\tau_{B}\right)\right) y_{B 1}}{\left.\Omega^{1 /(1-\theta)}\right)+\left(\frac{\left(1 /\left(1+\tau_{A}\right)\right) y_{A 2}+\left(1 /\left(1+\tau_{B}\right)\right) y_{B 2}}{\Omega^{1 /(1-\theta)}(1+i)}\right)}\right. \\
-\left(\frac{(1 / \alpha)\left(1 /\left(1+\tau_{A}\right)\right)\left(1+\left(\frac{1+\tau_{F}}{1 /\left(1+\tau_{H}\right)}\right)^{1-\theta}\right) y_{A 2}}{\Omega^{1 /(1-\theta)}(1+i)}\right)
\end{aligned}
$$




$$
\begin{aligned}
& c_{1}^{\overrightarrow{V V a}}=(1 / \alpha)\left(1 /\left(1+\tau_{A}\right)\right)\left(1+\left(\frac{1+\tau_{F}}{\left(\frac{1}{1+\tau_{H}}\right)}\right)^{1-\theta}\right)\left(\frac{1}{\Omega^{1 /(1-\theta)}}\right) y_{A 1} \\
& c_{1}^{\overrightarrow{I V b}}=\left(\gamma_{1} / \alpha\right)\left(1 /\left(1+\tau_{B}\right)\right)\left(1+\left(\frac{1+\tau_{F}}{\left(\frac{\gamma_{1}^{\alpha}}{1+\tau_{B}}\right)}\right)^{1-\theta}\right)\left(\frac{1}{\left(\left(\frac{\gamma_{1}^{\alpha}}{1+\tau_{B}}\right)^{1-\theta}+\left(1+\tau_{F}\right)^{1-\theta}\right)^{1 /(1-\theta)}}\right) y_{A 1} \\
& c_{1}^{\overrightarrow{I V C}}=\left(\gamma_{1}^{\alpha} / \alpha\right)\left(1+\tau_{B}\right)\left(1+\left(\frac{1+\tau_{F}}{\left(1+\tau_{B}\right) \gamma_{1}^{\alpha}}\right)^{1-\theta}\right)\left(\frac{1}{\left(\left(\gamma_{1}^{\alpha}\left(1+\tau_{B}\right)\right)^{1-\theta}+\left(1+\tau_{F}\right)^{1-\theta}\right)^{1 /(1-\theta)}}\right) y_{A 1} \\
& c_{1}^{\vec{V}}=(1 / \alpha)\left(1+\tau_{A}\right)\left(1+\left(\frac{1+\tau_{F}}{1+\tau_{H}}\right)^{1-\theta}\right)\left(\frac{1}{\left(\left(1+\tau_{H}\right)^{1-\theta}+\left(1+\tau_{F}\right)^{1-\theta}\right)^{1 /(1-\theta)}}\right) y_{A 1}
\end{aligned}
$$

where

$$
\begin{aligned}
& \Omega \equiv\left(\frac{1}{1+\tau_{H}}\right)^{1-\theta}+\left(1+\tau_{F}\right)^{1-\theta} \\
& 1+\tau_{H} \equiv\left(1+\tau_{A}\right)^{\alpha}\left(1+\tau_{B}\right)^{1-\alpha} \\
& \gamma_{1} \equiv\left((\alpha /(1-\alpha))\left(y_{B 1} / y_{A 1}\right)\right. \\
& \gamma_{2} \equiv\left((\alpha /(1-\alpha))\left(y_{B 2} / y_{A 2}\right)\right.
\end{aligned}
$$


Appendix Table 2. Intertemporal price ratios: benchmark case

$\frac{p_{1}^{I}}{p_{2}^{I}}=\frac{\left(\left(\left(1 /\left(1+\tau_{A}\right)\right)^{\alpha}\left(1 /\left(1+\tau_{B}\right)\right)^{1-\alpha}\right)^{1-\theta}+\left(1+\tau_{F}\right)^{1-\theta}\right)^{1 /(1-\theta)}}{\left(\left(\left(1+\tau_{A}\right)^{\alpha}\left(1+\tau_{B}\right)^{1-\alpha}\right)^{1-\theta}+\left(1+\tau_{F}\right)^{1-\theta}\right)^{1 /(1-\theta)}}<1$

$\frac{p_{1}^{I I a}}{p_{2}^{I I a}}=\frac{\left(\left(\left(1 /\left(1+\tau_{A}\right)\right)^{\alpha}\left(1 /\left(1+\tau_{B}\right)\right)^{1-\alpha}\right)^{1-\theta}+\left(1+\tau_{F}\right)^{1-\theta}\right)^{1 /(1-\theta)}}{\left(\left(\left(p_{A 2}^{I I a}\right)^{\alpha}\left(1+\tau_{B}\right)^{1-\alpha}\right)^{1-\theta}+\left(1+\tau_{F}\right)^{1-\theta}\right)^{1 /(1-\theta)}}<1$

where $\left(1+\tau_{B}\right) \gamma_{2}<p_{A 2}^{I I a}<1+\tau_{A}$

$\frac{p_{1}^{I l b}}{p_{2}^{I l b}}=\frac{\left(\left(\left(1 /\left(1+\tau_{A}\right)\right)^{\alpha}\left(1 /\left(1+\tau_{B}\right)\right)^{1-\alpha}\right)^{1-\theta}+\left(1+\tau_{F}\right)^{1-\theta}\right)^{1 /(1-\theta)}}{\left(\left(\left(p_{A 2}^{I l b}\right)^{\alpha}\left(p_{B 2}^{I l b}\right)^{1-\alpha}\right)^{1-\theta}+\left(1+\tau_{F}\right)^{1-\theta}\right)^{1 /(1-\theta)}}<1$

where $\gamma_{2} /\left(1+\tau_{B}\right)<p_{A 2}^{I l b}=\gamma_{2} p_{B 2}^{I l b}<\gamma_{2}\left(1+\tau_{B}\right)$

$\frac{p_{1}^{I I c}}{p_{2}^{I I c}}=\frac{\left(\left(\left(1 /\left(1+\tau_{A}\right)\right)^{\alpha}\left(1 /\left(1+\tau_{B}\right)\right)^{1-\alpha}\right)^{1-\theta}+\left(1+\tau_{F}\right)^{1-\theta}\right)^{1 /(1-\theta)}}{\left(\left(\left(p_{A 2}^{I I C}\right)^{\alpha}\left(\frac{1}{1+\tau_{B}}\right)^{1-\alpha}\right)^{1-\theta}+\left(1+\tau_{F}\right)^{1-\theta}\right)^{1 /(1-\theta)}}<1$

where $1 /\left(1+\tau_{A}\right)<p_{A 2}^{I l c}<\gamma_{2} /\left(1+\tau_{B}\right)$

$\frac{p_{1}^{I I I}}{p_{2}^{I I I}}=\frac{\left(\left(\left(1 /\left(1+\tau_{A}\right)\right)^{\alpha}\left(1 /\left(1+\tau_{B}\right)\right)^{1-\alpha}\right)^{1-\theta}+\left(1+\tau_{F}\right)^{1-\theta}\right)^{1 /(1-\theta)}}{\left(\left(\left(1 /\left(1+\tau_{A}\right)\right)^{\alpha}\left(1 /\left(1+\tau_{B}\right)\right)^{1-\alpha}\right)^{1-\theta}+\left(1+\tau_{F}\right)^{1-\theta}\right)^{1 /(1-\theta)}}=1$ 
$\frac{p_{1}^{I V a}}{p_{2}^{I V a}}=\frac{\left(\left(\left(p_{A 1}^{I V a}\right)^{\alpha}\left(\frac{1}{1+\tau_{B}}\right)^{1-\alpha}\right)^{1-\theta}+\left(1+\tau_{F}\right)^{1-\theta}\right)^{1 /(1-\theta)}}{\left(\left(\left(1 /\left(1+\tau_{A}\right)\right)^{\alpha}\left(1 /\left(1+\tau_{B}\right)\right)^{1-\alpha}\right)^{1-\theta}+\left(1+\tau_{F}\right)^{1-\theta}\right)^{1 /(1-\theta)}}>1$

where $1 /\left(1+\tau_{A}\right)<p_{A 1}^{I V a}<\gamma_{1} /\left(1+\tau_{B}\right)$

$\frac{p_{1}^{I V b}}{p_{2}^{I V b}}=\frac{\left(\left(\left(p_{A 1}^{I V b}\right)^{\alpha}\left(p_{B 1}^{I V b}\right)^{1-\alpha}\right)^{1-\theta}+\left(1+\tau_{F}\right)^{1-\theta}\right)^{1 /(1-\theta)}}{\left(\left(\left(1 /\left(1+\tau_{A}\right)\right)^{\alpha}\left(1 /\left(1+\tau_{B}\right)\right)^{1-\alpha}\right)^{1-\theta}+\left(1+\tau_{F}\right)^{1-\theta}\right)^{1 /(1-\theta)}}>1$

where $\gamma_{1} /\left(1+\tau_{B}\right)<p_{A 1}^{I V b}=\gamma_{1} p_{B 1}^{I V b}<\gamma_{1}\left(1+\tau_{B}\right)$

$\frac{p_{1}^{I V C}}{p_{2}^{I V c}}=\frac{\left(\left(\left(p_{A 1}^{I V c}\right)^{\alpha}\left(1+\tau_{B}\right)^{1-\alpha}\right)^{1-\theta}+\left(1+\tau_{F}\right)^{1-\theta}\right)^{1 /(1-\theta)}}{\left(\left(\left(1 /\left(1+\tau_{A}\right)\right)^{\alpha}\left(1 /\left(1+\tau_{B}\right)\right)^{1-\alpha}\right)^{1-\theta}+\left(1+\tau_{F}\right)^{1-\theta}\right)^{1 /(1-\theta)}}>1$

where $\left(1+\tau_{B}\right) \gamma_{1}<p_{A 1}^{I V c}<1+\tau_{A}$

$$
\frac{p_{1}^{V}}{p_{2}^{V}}=\frac{\left(\left(\left(1+\tau_{A}\right)^{\alpha}\left(1+\tau_{B}\right)^{1-\alpha}\right)^{1-\theta}+\left(1+\tau_{F}\right)^{1-\theta}\right)^{1 /(1-\theta)}}{\left(\left(\left(1 /\left(1+\tau_{A}\right)\right)^{\alpha}\left(1 /\left(1+\tau_{B}\right)\right)^{1-\alpha}\right)^{1-\theta}+\left(1+\tau_{F}\right)^{1-\theta}\right)^{1 /(1-\theta)}}>1
$$

